Portland State University

PDXScholar

9-30-1996

\title{
The Relationships among Coping, Control, and Adjustment to Cancer
}

\author{
Sharon Ann Johnson \\ Portland State University
}

Follow this and additional works at: https://pdxscholar.library.pdx.edu/open_access_etds

Part of the Psychology Commons

Let us know how access to this document benefits you.

\section{Recommended Citation}

Johnson, Sharon Ann, "The Relationships among Coping, Control, and Adjustment to Cancer" (1996). Dissertations and Theses. Paper 5280.

https://doi.org/10.15760/etd.7153

This Thesis is brought to you for free and open access. It has been accepted for inclusion in Dissertations and Theses by an authorized administrator of PDXScholar. Please contact us if we can make this document more accessible: pdxscholar@pdx.edu. 


\section{THESIS APPROVAL}

The abstract and thesis of Sharon Ann Johnson for the Master of Science in Psychology were presented September 30,1996, and accepted by the thesis committee and the department.

COMMITTEE APPROVALS:
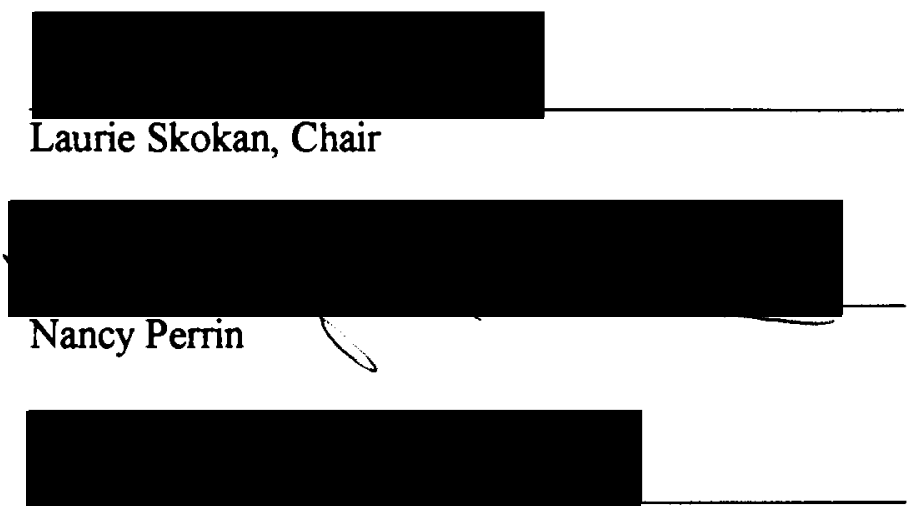

Ellen Skinner

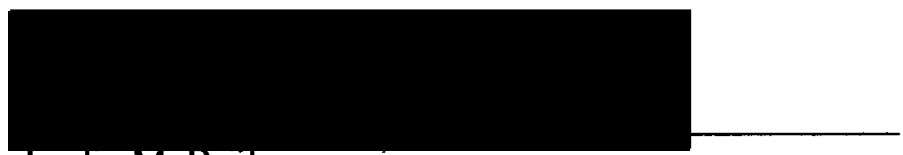

Leshe McBride

Representative of the Office of Graduate Studies

DEPARTMENT APPROVAL

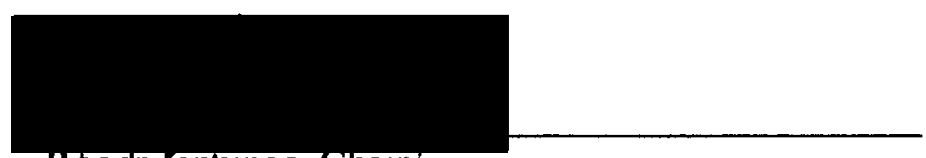

Rфger enhings, Chalr?

Departugnt of Psychology

ACCEPTED FOR PORTLAND STATE UNIVERSITY BY THE LIBRARY

by

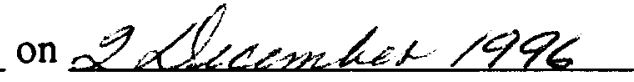




\begin{abstract}
An abstract of the thesis of Sharon Ann Johnson for the Master of Science in Psychology presented September 30, 1996.
\end{abstract}

Title: The Relationships among Coping, Control, and Adjustment to Cancer

This study proposed that a major function of coping is to regain perceptions of control that are threatened by the cancer experience and that perceived control mediates the relationship between coping and adjustment. Participants were 258 cancer patients, $61 \%$ women and $39 \%$ men, aged 29 to 93 years. A variety of cancer sites were represented with breast and prostate cancer the most prevalent. Patterns of coping, perceived control in four areas (symptom-emotion, relationship, medical care, and disease control), and emotional adjustment were measured. It was expected that a sixth pattern of coping, problem-focused, would emerge when additional problem-focused items were added to the Ways of Coping-Cancer inventory. However, the expected problem-focused pattern was not distinct from the seek and use social support pattern. It was suggested that seeking and using social support may be a problem-focused strategy when dealing with relationships that are altered by the cancer experience.

The study provided some support for the notion that symptom-emotion control has a greater influence than disease control on emotional adjustment as measured by the bipolar Profile of Mood States. However, all four areas of perceived control made 
substantial contributions to emotional adjustment.

The findings only partially supported the proposed model in which perceived control mediated the relationship between coping and adjustment. All five patterns of coping influenced perceived control, and perceived control was strongly associated with emotional adjustment. The cognitive escape-avoidant pattern of coping exerted an indirect (mediated) influence on emotional adjustment through perceived control. The behavioral escape-avoidant and focus on the positive patterns exerted both indirect and direct influences on emotional adjustment. While social support and distancing coping patterns were not predictive of emotional adjustment, they did predict perceived control. It was suggested that efforts to bolster cancer patients' emotional adjustment should focus on both teaching positive coping strategies and on efforts to increase perceptions of control. 
THE RELATIONSHIPS AMONG

COPING, CONTROL, AND ADJUSTMENT TO CANCER

by

SHARON ANN JOHNSON

A thesis submitted in partial fulfillment of the

requirements for the degree of

MASTER OF SCIENCE

in

PSYCHOLOGY

Portland State University

1996 


\section{TABLE OF CONTENTS}

PAGE

The Relationships among Coping, Control and Adjustment to Cancer ....... 6

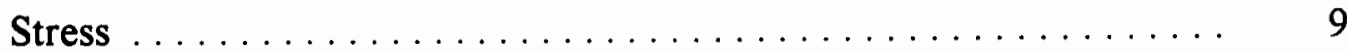

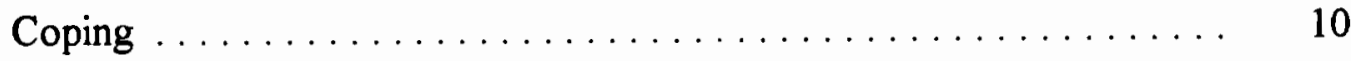

Control .................................. 15

A Revised Model . . . . . . . . . . . . . . . . . . . . . . 21

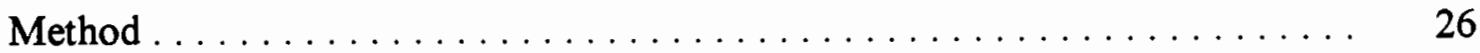

Participants .............................. 26

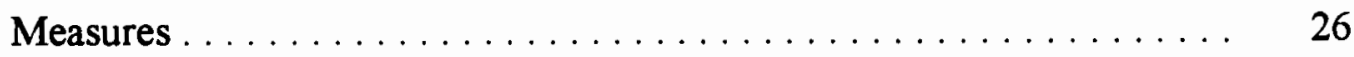

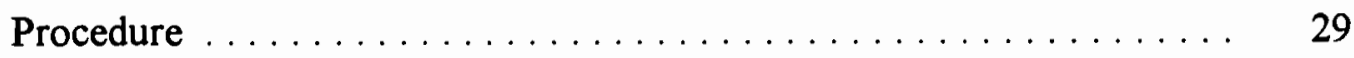

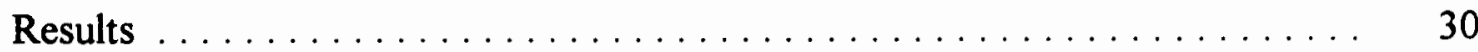

Patterns of Coping. . . . . . . . . . . . . . . . . 33

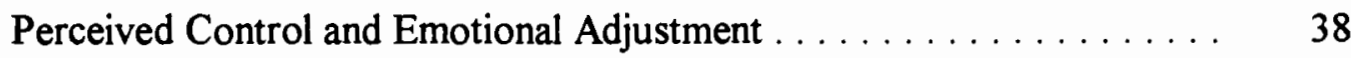

Coping, Perceived Control, and Emotional Adjustment. ......... 43

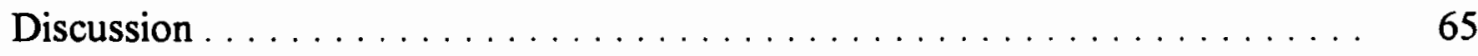

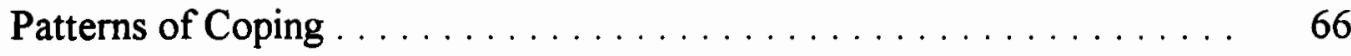

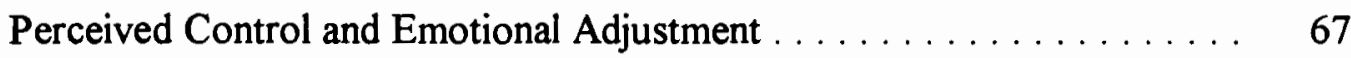

Coping, Perceived Control, and Emotional Adjustment . . . . . . . . . 69

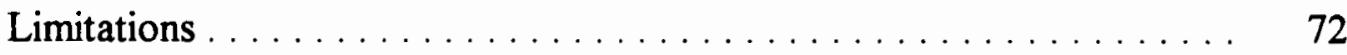

(table continues) 


\section{TABLE OF CONTENTS}

(Continued)

\section{PAGE}

References............................ 74

Appendix A . . . . . . . . . . . . . . . . . . . . . . . 77

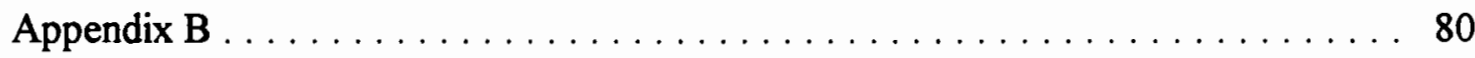




\section{The Relationships among Coping, Control, and Adjustment to Cancer}

When confronted with threatening events, people display substantial adaptability. Taylor (1983) reported anecdotal responses from cancer patients that demonstrated this adaptability. Many patients reported that cancer had made them see their lives in a new light and they felt somehow better off as a result of their new knowledge. Others responded to cancer by expressing a new found ability to understand themselves, by finding satisfaction in an inner strength they previously didn't know they had, and by finding new meaning in their relationships. In searching for explanations for this adaptability, two major research themes emerged. The first was represented by research that explored the relationship between coping and adjustment; the second by research that explored the relationship between control and adjustment. Folkman (1984) provided a theoretical perspective which merged these two major themes. This merger has been used as a vehicle for discussing the research literature surrounding stress, coping, control, and adjustment among cancer patients and for developing a model of how coping and control may influence emotional adjustment among cancer patients.

Folkman (1984) analyzed the role of personal control from the perspective of a cognitive theory of coping (Folkman \& Lazarus, 1980). This theory proposed that cognitive appraisal and coping are mediators of stress and stress-related outcomes. Control plays a dual role within Folkman's theory in that it affects the cognitive appraisal phase of the process and can be seen as an outcome of coping. The theory 
might be represented as follows:

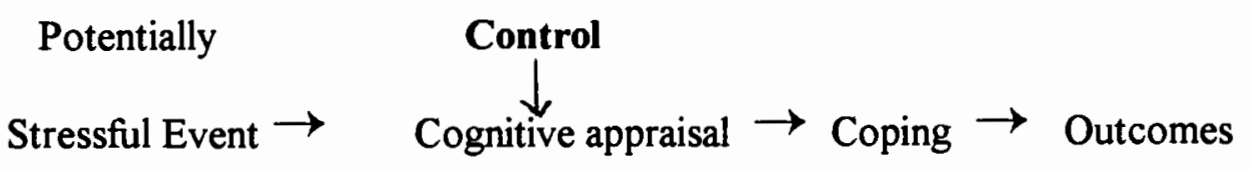

. Adjustment

\section{Control}

Folkman (1984) defined stress as "a relationship between the person and the environment that is appraised by the person as taxing or exceeding his or her resources and as endangering his or her well-being" (p. 840). Thus, stress is the relationship between the environment in which the event occurred and the person. The idea that stress is a relationship between the person and the environment implies that stress is dynamic and responds to feedback. Suppose that the environmental stressor for a cancer patient is loss of physical mobility. Stress is the relationship between the person and the loss of mobility. The person may respond to the stress by attempting to reduce mobility requirements (i.e., changing the self) or by finding alternative ways of becoming mobile (i.e., changing the environment). Feedback from the person in the form of reduced mobility needs or from the environment in the form of alternative means of mobility results in a new relationship between the person and the environment. The result is that the stress the person experiences is changed.

According to Folkman, when a potentially stressful event occurs, the individual engages in an appraisal process. The appraisal process has two phases. First, the individual determines whether the event poses a threat or challenge to well-being. 
Perceptions of control affect the initial appraisal. If the event can be controlled by the person, it is less likely to be perceived as challenging or threatening. On the other hand, if the event cannot be controlled by the individual, it is more likely to be appraised as challenging or threatening, and therefore, stress producing.

Given that the event is appraised as threatening or challenging, the appraisal process proceeds to the second phase. In the second phase, referred to as secondary appraisal, coping resources are evaluated and the individual determines what can be done to reduce stress. During secondary appraisal, beliefs about the possibilities for control in the specific situation become important. These beliefs have implications for the type of coping that will be employed. If the stressor is deemed uncontrollable, the individual may have to rely on attempts to manage emotional reactions to the resulting stress. However, if the stressor is perceived as controllable, the individual can attempt to manage the stress itself as well as his or her emotional reactions (Folkman, 1984).

Folkman (1984) defined coping as "cognitive and behavioral efforts to master, reduce, or tolerate the internal and/or external demands that are created by the stressful transaction" (p. 843). Attempts to manage stress are defined as coping regardless of whether the attempts were successful. Within Folkman's framework, coping has two functions. One is regulation of emotion (emotion-focused coping) and the other is managing the problem (problem-focused coping). When emotion-focused coping is employed, the individual seeks to gain control over the emotions associated with the stress. One way of achieving control over emotional reactions is to alter the meaning of an event. For example, a cancer patient might decide that the cancer has helped her find 
Coping and Control 9

new meaning in her social relationships. Problem-focused coping, on the other hand, is aimed directly at managing, or gaining control over, the troubled person-environment relationship (i.e., the stress). The individual can focus on changing either the person or the environment. Consider the loss of mobility example presented above, individuals in this situation can either change their needs for mobility or change the way mobility is achieved. Whether they focus on changing the person or the environment, the objective of coping efforts is to gain control over the troubled person-environment relationship. When viewed in this manner, control can be seen as a product of the coping process.

In sum, control plays two roles within the framework proposed by Folkman (1984). First, control affects the appraisal process by influencing whether the event is perceived as stressful and the choice of coping strategies that will be employed.

Second, control can be seen as an outcome of the coping process. Thus, control can be seen as both an antecedent of coping and as an outcome of coping. Clearly, the process is complex and each component requires careful consideration. The remainder of this section will review the literature on stress, coping and control as they relate to cancer, and propose a revision to Folkman's model.

\section{$\underline{\text { Stress }}$}

There seems little doubt that a diagnosis of cancer would be appraised as threatening to well-being and fit Folkman's definition of stress. Cancer threatens both a patient's physical health and emotional well-being. Cancer patients may have to deal with painful and frightening symptoms, uncertainty about the course of the disease and its treatment, pain and side effects associated with treatment, and changes in social 
relationships. Dunkel-Schetter, Feinstein, Taylor, and Falke (1992) identified the most frequent problems associated with cancer as limitations in physical ability, pain, and problems in social relationships.

Defining stress as a relationship between the person and the environment permits viewing stress as a dynamic process rather than as a single noxious event. It is not simply the diagnosis of cancer that creates stress, but all of the uncertainties, symptoms, and treatments associated with the diagnosis. In a study of 117 women followed over the course of a cancer diagnosis, Stanton and Snider (1993) found that the emotional impact of the disease varied over the course of the medical process. Distress and perceived threat were most pronounced shortly after diagnosis. After surgery, distress levels fell back to levels comparable to the distress felt during the period between the initial medical contact and the biopsy. Thus, it appears that when considering the stresses associated with cancer, it would be beneficial to view stress as a process which changes over the course of the disease.

\section{Coping}

A number of studies have addressed the effects of particular coping strategies on adjustment outcomes (Dunkel-Schetter et al., 1992; Felton \& Revenson, 1984; Friedman, Baer, Lewy, Lane, \& Smith, 1989; Stanton \& Snider, 1993). In general, these studies have found that avoidant coping strategies are associated with poor adjustment to cancer, while more active positive coping strategies are associated with more favorable adjustment.

Dunkel-Schetter and associates (1992) studied coping among 668 cancer 
Coping and Control 11

patients ranging from 21 to 88 years of age and including both men (22\%) and women (78\%). A wide variety of cancers were represented; breast (42\%), gastrointestinal $(13 \%)$, circulatory or lymph cancers $(11 \%)$, female reproductive $(9 \%)$, respiratory $(8 \%)$, musculoskeletal (6\%), head and neck cancers (5\%), and other (6\%). All stages of cancers were represented. Time since diagnosis ranged from newly diagnosed to diagnosed up to five years ago.

In this broad sample, five patterns of coping were identified using factor analysis. The five patterns were (a) seek and use social support, (b) cognitive escapeavoidance, (c) distancing, (d) focus on the positive, and (e) behavioral escapeavoidance. With the exception of seek and use social support, the items which comprised each of the patterns of coping seemed fairly intuitive. For example, distancing included items such as tried to keep my feelings from interfering, didn't let it get to me, and went on as if nothing was happening. Seek and use social support, however, was not so unidimensional. This factor included not only social support items such as looked for sympathy or understanding and asked a friend or relative for advice, but some problem-focused aspects such as tried to get professional help, tried to find out as much as I could, tried not to close off options, and made a plan of action and followed it.

Dunkel-Schetter and associates (1992) found little evidence that patients adopt any particular coping style. Instead, it appeared that individuals use a wide variety of different coping patterns in dealing with cancer. Specific problems were not related to specific patterns of coping. In other words, no particular coping patterns were used to 
deal with relationship problems relative to, for example, physical problems. The use of particular coping patterns did, however, vary with the perceived stressfulness of the problem. When problems were perceived as particularly stressful, cancer patients engaged in more coping through social support and were more likely to use both forms of escape-avoidance.

Distancing was the most frequently used coping pattern. It was used by nearly all of the subjects and was not associated with time since diagnosis. The frequent use of distancing is consistent with findings reported by Folkman and Lazarus (1980) which indicated that emotion-focused coping was more likely to be used than problem-focused coping for health problems, especially when the problem was appraised as uncontrollable. In fact, all of the factors identified by Dunkel-Schetter et al. (1992), with the possible exception of seek and use social support which contained some problem-focused items, might be viewed as emotion-focused.

Other coping patterns were used to varying degrees depending on the characteristics of the subject or the stressfulness of the situation. For example, focusing on the positive tended to be used more by people who were very religious and younger. Unlike seek social support and both forms of escape-avoidance, all of which were associated with higher levels of emotional distress, focusing on the positive was associated with less emotional distress. Interestingly, there were differences among religious groups in their use of focusing on the positive. Catholics were most likely to use this coping pattern, followed by Protestants, and finally by Jews. Despite the identification of particular groups who were more likely to use particular coping 
patterns, it should be emphasized that most cancer patients used multiple patterns of coping (Dunkel-Schetter et al., 1992).

Stanton and Snider (1993) used the factors identified by Dunkel-Schetter and her colleagues to examine the relationships between coping patterns and adjustment in a longitudinal study of breast cancer patients. Measurements were gathered at three time points, prebiopsy, postbiopsy, and postsurgery. Three prebiopsy coping strategies were associated with postbiopsy adjustment. Coping through seeking social support before biopsy was beneficial after diagnosis. Coping by focusing on the positive had mixed effects. When women focused on the positive prebiopsy and then were diagnosed with cancer, they experienced less vigor postbiopsy than women diagnosed with cancer who had not relied on focusing on the positive prebiopsy. However, after surgery those who had initially coped by focusing on the positive were no worse off in terms of vigor than other women. This finding led Stanton and Snider to speculate that creating a positive illusion (Taylor \& Brown, 1988) may not be uniformly beneficial. Some recovery time seemed to be necessary to shift positive focus to some other aspect of their lives. The third prebiopsy coping pattern that affected postbiopsy and postsurgery adjustment was cognitive avoidance. Prebiopsy cognitive avoidance was associated with postbiopsy and postsurgery negative affect. Although the results of this study are generally consistent with other studies of coping and adjustment, due to small sample sizes, caution should be used in generalizing the results. Although the initial sample included 117 women, only 30 were included in the postsurgery cancer group.

Friedman et al. (1989) also examined the relationship between coping and 
adjustment among breast cancer patients. Results were based on a sample of 67 women aged 32-69 years. Results were similar to those of Stanton and Snider (1993) in that an avoidant coping style was associated with poorer measures of adjustment.

Felton and Revenson (1984) evaluated the role of coping in explaining psychological adjustment in a study of 151 patients with four chronic illnesses. Two of the illnesses, cancer and rheumatoid arthritis, were viewed as noncontrollable by the researchers, and two, hypertension and diabetes, were viewed as controllable. Felton and Revenson examined only two coping strategies, information seeking and wishfulfilling fantasy. Information seeking was measured by five items; looking up medical information, reading books or magazines or watching TV programs about the illness, finding several different solutions to a problem, asking someone other than a physician for advice, and making a plan and following it. Reliability for the five items was low, .67 in the initial interview and .55 in a follow-up interview. However, information seeking as measured by these items was included in the study based on the authors' judgments of its theoretical and practical importance. Wish-fulfilling fantasy was measured using eight items such as wishing you could change what happened, wishing you could change how you feel, and hoping for a miracle. Alpha coefficients were at acceptable levels for this measure, .79 and .81 . Consistent with findings reported earlier, the more active coping style, seeking information, was associated with positive adjustment while wish-fulfilling fantasy was associated with poorer adjustment. Although several researchers have examined coping strategies and their association with various measures of adjustment as they relate to cancer, they fail to 
describe how coping might lead to differential adjustment. It seems clear that cognitive avoidance as a coping strategy is associated with higher levels of distress and poorer mood, but it remains unclear whether cognitive avoidance leads to poorer outcomes or whether higher levels of distress initially lead to the use of cognitive avoidance which simply fails to alleviate the distress.

\section{Control}

Studies examining the relationship between control and adjustment to cancer have employed a variety of measures of control. Some researchers have developed questions specifically addressing perceived control over the course of the cancer as well as over the consequences of the cancer (Taylor, Lichtman, \& Wood, 1984; Thompson, Sobolew-Shubin, Galbraith, Schwankovsky, \& Cruzen, 1993), while others have relied on general measures such as the Multidimensional Health Locus of Control Scale (Burish et al., 1984; Friedman et al., 1989). The findings of these studies appear to be related to the types of measures used. Studies using more specific measures have found positive relationships between control and emotional adjustment, while studies using more general measures have found no relationship or mixed results.

Taylor et al. (1984) examined cancer patients' attributions about the causes of their cancers and beliefs about whether they or someone else could control their cancers. Subjects were 78 breast cancer patients. In general, most (56\%) of these breast cancer patients felt they had some or a lot of control over their cancers. Among these patients, control was derived through changes in attitude (e.g., taking things more easily, not getting upset) or through changes in their lives (e.g., changes in diet). An 
even greater number of subjects $(68 \%)$ believed that others could control their cancers. The majority ( $78 \%$ ) of those who believed that others could control their cancers, felt that their physicians or treatments provided control. Substantially fewer $(10 \%)$ believed God or a therapist provided control.

Attributions about the cause of the cancer were not related to adjustment. However, psychological control was related to better adjustment. Both a belief that one can control one's own cancer and a belief that others can control it were positively associated with adjustment (Taylor et al., 1984).

Lowery, Jacobsen, and DuCette (1993), in a study of 195 women with breast cancer, also examined beliefs about whether or not cancer could be personally controlled. Fewer of these subjects ( $45 \%$ compared to $56 \%$ in Taylor et al., 1984) believed they had some or a lot of control over their cancers. The majority (55\%) believed they had little or no control over the course of their cancers. Among those believing they had at least some control, most felt that improving their health habits, complying with treatments, and/or adopting a positive attitude gave them control. Consistent with Taylor et al., Lowery and associates found that the belief that others, a physician, God, or chance, could control their cancer was stronger than a belief in direct personal control.

Lowery et al. (1993) examined the relationship between three measures of control (retrospective control, health locus of control, and loss of control) and adjustment. Retrospective control was measured by asking "To what extent do you feel that the cause of your cancer is something that you (someone else) could have done 
something about, had you (they) foreseen it?" (p. 42). Health locus of control was measured using the Multidimensional Health Locus of Control Scale. Loss of control was measured by asking patients to rate on a 4-point scale whether they had experienced any loss of control since their cancer diagnosis. No relationship was found between retrospective control and adjustment, nor was there a significant relationship between health locus of control and adjustment. Loss of control, however, was found to be a significant predictor of poor adjustment and of overall distress. Thus, it appears that the relationship between control and adjustment depended on the type of control measure used.

Thompson and associates (1993) explored perceptions of control among 71 cancer patients, 26 men and 45 women. Among the issues addressed were (a) the importance of perceived control over the cancer itself versus control over the consequences of the cancer, and (b) the role of perceived control when poor outcomes, as measured by physical limitations and marital discord, were being received. The findings indicated that it was somewhat important to believe that you can control the cancer, but it was even more important to be able to control the consequences of the cancer (i.e., daily emotions and physical symptoms). Contrary to the perspective that control must be reality based to be beneficial, those who experienced more physical limitations were better off psychologically when they had a strong sense of control. Their strong sense of control, however, was over emotions and physical symptoms, not over the course of the disease. Interestingly, a number of strategies for maintaining a sense of control were identified. Among these were items such as faith, 
communication, following doctor's orders, reading and research, and maintaining a positive attitude. Although Thompson does not refer to these strategies as coping, it seems likely that coping efforts among these patients were directed toward establishing areas of control. While Thompson found a relationship between perceptions of control and positive adjustment, it is not possible to conclude from these findings that perceptions of control cause positive adjustment. The possibility remains that positive adjustment may lead to increased perceptions of control.

Some indication that perceptions of control lead to improved emotional states was reported by Taylor, Helgeson, Reed, and Skokan (1991). In a longitudinal study of 47 patients with coronary heart disease, these researchers found that higher perceptions of control led to reduced anxiety and depression. It seems reasonable to expect that control would provide similar advantages for cancer patients.

Jenkins and Pargament (1988) examined perceived control over cancer and perceived control over emotional reactions among 61 cancer patients including both males (35.5\%) and females (64.5\%). Perceived control over emotional responses were measured using items selected from a perceived inevitability of emotional response scale. Consistent with Thompson et al.'s (1993) findings, perceptions of control over the cancer were found to be somewhat important. Perceptions of control over the cancer were related to lower perceived life threat, $\underline{r}=-.13, \underline{p}<.05$. Higher levels of perceived inevitability of emotional responses were negatively related to global adjustment, $\underline{\underline{r}}=-.25, \mathfrak{p}<.05$. These correlations led Jenkins and Pargament to suggest that higher levels of perceived control over the cancer promote more favorable 
adjustment, but that perceived control over emotional responses may be a more important component of adjustment to cancer. Although these conclusions are consistent with those reported by Thompson and associates, they appear to be based on two assumptions. First, that lower life threat is associated with better adjustment. The reported association between life threat and global adjustment was only marginally significant, $\mathfrak{r}=-.26, \mathfrak{p}<.06$. The second assumption seemed to be that higher perceived inevitability of emotional reactions reflects lower perceived control of emotional reactions. Clearly, Jenkins and Pargament's findings are only suggestive of their conclusions.

Burish et al. (1984) examined the relationships among health locus of control, measures of arousal, and affect among 62 cancer chemotherapy patients. Locus of control measures were collected prior to an intervention designed to train patients in muscle-relaxation and biofeedback techniques for the reduction of the side effects of treatment. Findings indicated that patients with a high external locus of control orientation benefited more from the intervention than did patients with lower locus of control orientations. The patients with a high external locus of control exhibited lower levels of physiological arousal as well as less negative affect. In contrast, patients who scored high on the internal locus of control scale reported feeling more anxious after the training intervention. Although they reported more anxiety after training, these patients did exhibit lower pulse rates in the last training session. However, the lower pulse rates had disappeared by the follow-up session. These findings led Burish et al. to conclude that an internal locus of control may be maladaptive for some cancer patients if they are 
offered an intervention which requires that they exercise greater control and responsibility. Although this may seem counter-intuitive, an explanation was offered by Wortman and Dunkel-Schetter (1979). They suggested that patients with a high internal locus of control may be anxious and despondent over their loss of control of their health, and, therefore, may not take advantage of treatment opportunities which become available.

In two additional studies, no relationships between control and adjustment were found. Stanton and Snider (1993) reported that neither generalized nor specific control expectancies were predictive of mood, which was used as a measure of adjustment. Generalized control expectancies were measured using two questions, "what happens to me is my own doing" and "I have often found that what is going to happen will happen." Specific control expectancies were measured by asking whether subjects' cancer experiences were ones that they could change or do something about and whether their cancer experiences were ones that must be accepted or gotten used to. Perhaps the reason that no relationship between control and mood was found was that both the generalized and specific measures used tended to be more general in nature than questions included in the studies reviewed above.

Friedman et al. (1989) also found no relationship between control and adjustment to cancer. Again, the lack of relationship may stem from the lack of specificity in the measures of control that were employed. Friedman and associates used the health locus of control scale which was developed for health-related behaviors in general. Other researchers, for example Taylor et al. (1984), used instruments 
designed specifically for cancer.

In sum, it appears that higher levels of perceived control are positively related to favorable adjustment when the measures of control have been specifically designed to tap patients' perceived control over their cancers or the consequences of their cancers. However, when measures are more general or when measures of locus of control have been used, the results have not been so clear cut. An analysis by Skinner (1995) provides some insight into the differential effects of locus of control orientation. Skinner argued that internal attributions do not lead to differential outcomes because control has both negative and positive effects, but because internal attributions lead to differential control expectations. When an individual makes an internal attribution for control, it can either lead to an expectation of increased future control or of decreased future control. Thus, it appears that locus of control may not be an appropriate measure when the focus of interest is patients' perceived control of the stressors associated with cancer.

\section{$\underline{\text { A Revised Model }}$}

The research on perceived control of cancer suggested that roughly half of cancer patients view cancer as beyond their personal control (Taylor et al., 1984; Lowery et al., 1993). Folkman (1984) contended that when the stressor was uncontrollable, emotion-focused coping would be employed. The prevalence of emotion-focused patterns of coping was apparent in Dunkel-Schetter et al.'s (1992) study. With the exception of the social support seeking factor which contained some problem-focused elements (e.g., seeking information and keeping options open), all of 
the factors identified were comprised of coping efforts primarily directed at regulating emotions. The work by Thompson and associates (1993) and Jenkins and Pargament (1988) suggested that perceptions of control of the cancer and of the consequences of the cancer were important correlates of positive adjustment with control of the consequences being of greater importance. Thus, it appears that a major function of coping may be to redefine the cancer experience in a manner which permits the cancer patient to regain perceptions of control.

Based on this review of coping and control literature, a modification of Folkman's (1984) theory for research purposes is proposed:

$\begin{array}{lllll}\text { Stress of } & \text { Appraisal of } & \text { Perceived } & \text { Emotional } \\ \text { cancer } & \rightarrow & \text { control } & \rightarrow \text { Coping } \rightarrow \text { control } \rightarrow \text { Adjustment } \\ \text { diagnosis } & \text { possibilities }\end{array}$

In the revised model, coping is seen as directed specifically toward regaining control rather than as simply a byproduct of the coping process. There are a multitude of problems that threaten the cancer patient's well-being. Among them are pain, side effects of treatment, problems with relationships, and uncertainty about the future. Coping strategies are viewed within this model as efforts to regain control in these problem areas. In contrast to Folkman's model, this model is based on the belief that perceived control mediates the relationship between coping and adjustment.

The proposed framework in which control is included at two stages is consistent with Rothbaum, Weisz, and Snyder's (1982) two-process model of control. Rothbaum 
and associates argue that people seek both primary and secondary control. Primary control involves bringing the environment into line with the individual's wishes.

Individuals are likely to seek primary control when they perceive the stressor as one they can personally influence. For cancer patients, if fear of recurrence of the cancer is the stressor, efforts to avoid recurrence through changes in diet or through exercise would constitute attempts to achieve primary control. The individual may also attempt to gain secondary control, particularly if the stressor cannot be directly influenced. Secondary control is attained by bringing the self into line with the environment. Secondary control can be achieved through several methods. Individuals may align themselves with powerful others such as their doctors or God. They may choose to perceive themselves as extremely lucky people, thus, believing that recurrence of the cancer is unlikely. Another possibility is that they might choose to redefine the situation in a manner that would permit them to gain understanding and meaning from the uncontrollable event, in this case, the cancer.

Attempts to achieve primary and secondary control should not be viewed as mutually exclusive. Rothbaum et al. (1982) argued that optimal adaptation involves a balance between primary and secondary control. When the stressful event is perceived as amenable to direct control, the individual may engage in problem-focused coping. However, the individual may seek simultaneously to bring the self into line with the environment until some balance between primary and secondary control reduces the experienced stress. In a complex situation such as dealing with cancer, this view of control as involving two processes seems particularly appropriate. Since the patient 
must live with the diagnosis over an extended period, the transaction between the person and environment changes. Certain aspects are amenable to direct control and others are not.

The advantages of adopting the proposed model lie in the possibilities for interventions as well as the possibilities for further research. Interventions could be aimed at helping the cancer patient identify consequences of the cancer situation which can be controlled. Coping skills training might help the patient gain control in these areas. For example, interventions directed at pain management might help the patient gain control over pain. Another possibility might be to help patients identify the problematic areas in their social relationships. Coping skills training would be aimed at helping individuals regain control of their relationships. Interventions should be broad, covering many areas, and coping skills training should emphasize flexibility in applying coping methods. Dunkel-Schetter and associates (1992) found that positive adjustment was related to the use of a variety of coping patterns.

The research reported herein focuses on the Coping $\rightarrow$ Perceived Control $\rightarrow$ Emotional Adjustment portion of the model presented earlier. The overall goal was to examine how coping and control may combine to lead to positive outcomes. To accomplish this goal, coping was examined in light of the five coping patterns established by Dunkel-Schetter et al. (1992). Since Folkman's (1984) analysis of the role of control and coping in the stress-adjustment process relied heavily on a distinction between problem-focused and emotion-focused coping, one might have expected a problem-focused pattern of coping to emerge in Dunkel-Schetter's analysis. 
Coping and Control 25

A possible explanation for the lack of a problem-focused pattern is that the items used to measure coping contained relatively few items that directly address problem solving. It was expected that the addition of some problem-focused items would result in a sixth pattern of coping.

Control was incorporated using four areas of control used by Thompson et al. (1993); symptom-emotion control, relationship control, medical care control, and disease control. An overall measure of emotional adjustment was derived from the Profile of Mood States-Bipolar. Four hypotheses were examined:

H1: A sixth pattern of coping, problem-focused, will emerge when additional problem-focused coping alternatives are added to the Ways of Coping-Cancer inventory (WOC-CA).

$\mathrm{H} 2$ : Perceptions of symptom-emotion control will have a greater influence on emotional adjustment than will perceptions of disease control. While it is believed that relationship control and medical care control will influence adjustment, no predictions concerning their relative magnitudes have been made.

H3: The relationship between coping and emotional adjustment will be mediated by perceived control.

H4: Perceived control will explain variation in adjustment over and above that which is explained by coping alone. 


\section{Method}

\section{$\underline{\text { Participants }}$}

Participants included 258 cancer patients recruited through Providence Health System's tumor registry (85\%) and through support groups (15\%) held at Providence Hospitals in Portland, OR. The sample included $61 \%$ women and $39 \%$ men. Participants ranged from 29 to 93 years of age with a mean age of 62 years. Socioeconomic status of the participants was relatively high with $38 \%$ of the sample reporting that they held college degrees and $46 \%$ with incomes over $\$ 40,000$ per year. Ninety-six percent of the sample were white. A variety of cancer sites were represented with breast cancer being the most prevalent (37\%). Twenty-one percent had prostate cancer, $8.4 \%$ female reproductive cancer, $7.2 \%$ colon/rectal cancers, $5.2 \%$ cancer of the face, head or neck, $4.0 \%$ lung cancer, and $16.8 \%$ other cancers (including bladder, lymph, skin cancer, etc.). Time since diagnosis of either a new cancer or a recurrence ranged from one month to nine years. The mean time since diagnosis was 21 months and the median was 18 months.

\section{$\underline{\text { Measures }}$}

The questionnaire included demographics and personal items related to patients' medical conditions, health care providers, and satisfaction with support services available to them, as well as measures of stressors, coping, control, and adjustment. Stressors were measured using an inventory of problem situations associated with cancer. Since the data were collected as part of a larger study addressing the needs of cancer patients, not all of the data were relevant to the present study. In addition to 
some demographic and personal items, measures of health status, coping, perceived control, and adjustment were used in the current study.

Health status was measured on a 4-point scale; poor (I), fair (2), good (3), and excellent (4). Since few of the respondents rated their health as poor $(2.7 \%)$, the poor and fair (16.0\%) categories were subsequently combined into one category.

Coping strategies were measured using the Ways of Coping-Cancer (WOC-CA) inventory which was used by Dunkel-Schetter et al. (1992, adapted from Lazarus \& Folkman, 1984). The WOC-CA inventory included 49 items which were supplemented with five items written for the current study and aimed at tapping problem-focused coping strategies. Respondents were asked how often in the past 6 months they had tried to manage their cancer-related problems using each of the WOC-CA items. Responses were measured on a 5-point scale with options never (0), rarely (I), sometimes (2), often (3), and very often (4). Responses were later recoded to range from 1 to 5 . The 49 original items and five additional items were used to construct six subscales corresponding to the five patterns of coping identified by Dunkel-Schetter plus an additional problem-focused subscale. Means of the items answered for each subscale were calculated and used as the score for a respondent if $75 \%$ of the items for that subscale were answered. Reliability coefficients for the six coping subscales ranged from .72 to .87 (see Appendix A for a complete listing of the items, subscales, and reliability coefficients).

Perceived control was measured using 16 items constructed by Thompson et al. (1993). Subjects were asked to rate the amount and effectiveness of their control in 
eight areas; (a) emotions, (b) physical symptoms, (c) relationship with spouse, (d) relationships with family, (e) relationships with friends, (f) medical treatments, (g) medical information, and $(\mathrm{h})$ progression of the disease. Amount and effectiveness were rated on 7-point scales ranging from 1-no control at all to 7-a great deal of control for amount, and from 1-not at all effective to 7-very effective for effectiveness.

Measures of perceived control in four areas were calculated using the amount and effectiveness ratings; symptom-emotion control (4 items), relationship control (6 items), medical care control (4 items), and disease control ( 2 items). Except for relationship control, mean scores were calculated if the respondent answered at least $75 \%$ of the items for that subscale. Since two of the relationship control items were relevant for only married respondents, only four of the six relationship control items needed to be answered to calculate a relationship control score. Means were calculated using only those items that were answered. Reliability coefficients for the four areas of perceived control ranged from .75 to .92 . The specific items included in each area of control and the reliability coefficients for each area appear in Appendix B.

Adjustment was measured using the bipolar Profile of Mood States (POMS-BI; Lorr \& McNair, 1988) which includes 72 adjectives each rated on a 4-point scale with regard to mood within the past week. The adjectives were combined into six subscales (e.g., Composed-Anxious, Agreeable-Hostile) which were then summed for a single index of emotional state which was used as an overall measure of emotional adjustment. The reliability coefficient for the overall measure was .94 . 


\section{Procedure}

Two methods of data collection were used. The majority $(\underline{n}=218$ or $85 \%)$ of participants were recruited using Providence Health System's tumor registry.

Prospective participants were mailed a packet containing a letter of introduction from Providence, a questionnaire, and a postcard which was to be returned if the patient chose not to participate. The letter of introduction explained the nature of the research and assured participants of the confidentiality of their participation and responses. After approximately three weeks, a reminder letter was sent to those participants who had not returned a completed questionnaire or a postcard indicating that they did not wish to participate. Initially, 840 questionnaires were mailed. Of the initial 840 , it was discovered that 109 were not available to participate because of death (59), lack of forwarding address (48), or dementia (2). Response rates were calculated on the remaining 731 potential participants. Completed questionnaires were received from 218 cancer patients, a response rate of $30 \%$. Refusal postcards were received from 98 potential participants (13\%) and there was no response from $415(57 \%)$.

Due to a much lower response rate than anticipated, the sample drawn from the tumor registry was supplemented by distributing questionnaires at support groups. An additional 40 respondents (15\%) were obtained using this effort. Sex and marital status of respondents recruited through support groups were not different from those recruited through the tumor registry. However, respondents recruited through support groups tended to be younger and to have completed the questionnaire a greater number of months since diagnosis. Support group respondents had a mean age of 54 years versus 
Coping and Control 30

64 years for those recruited from the tumor registry, $\mathrm{E}(1,252)=17.4, \mathfrak{p}<.01$. Mean number of months since diagnosis or recurrence was 34 months for those recruited from support groups versus 19 months for those recruited from the tumor registry, $\underline{\mathrm{F}}(1,244)=$ $33.3, \mathfrak{p}<.01$.

\section{Results}

Due to the complexity of the relationships among stress, coping, control, and emotional adjustment, portions of the proposed model were examined separately. For example, $\mathrm{H} 1$ related to only the coping portion of the model, while $\mathrm{H} 2$ related to the perceived control $\rightarrow$ emotional adjustment portion of the model. $\mathrm{H} 3$ and $\mathrm{H} 4$ related to the coping $\rightarrow$ perceived control $\rightarrow$ emotional adjustment portion. The stress $\rightarrow$ appraisals of control possibilities portion was not examined in this study.

Means, standard deviations, the possible range, and the actual range for each of the coping and control subscales and for overall adjustment appear in Table 1. The expected problem-focused pattern of coping did not emerge in later analyses as a distinct construct and was not included in Tables 1 and 2. Distancing was the coping pattern (subscale) that tended to be used most frequently $(\underline{\mathrm{M}}=3.4)$ and behavioral escape-avoidance was used least $(\underline{M}=2.3)$. Beliefs about the amount and effectiveness of control in the four areas examined tended to be clustered around a 5.0 on a 7-point scale, indicating that these cancer patients believed they had at least some control over their cancers and its effects on symptoms-emotions, relationships, and medical care. Belief that one could control the disease tended to be somewhat lower $(\underline{M}=4.5)$ than 
beliefs in symptom-emotion, relationship, and medical care control.

Correlations among the subscales are displayed in Table 2. The coping subscales were positively and fairly strongly correlated with one another. Although the coping

Table 1

Means, Standard Deviations, Possible Range, and Actual Range

\begin{tabular}{lllll}
\hline Subscale & $\underline{M}$ & $\underline{\mathrm{D}}$ & Possible range & Actual range \\
\hline
\end{tabular}

Patterns of Coping

Seek and use social support 3.0

0.77

$1-5$

$1.00-4.55$

Cognitive escape-avoidance

2.9

0.70

$1-5$

$1.00-4.44$

Distancing

\section{4}

0.62

$1-5$

$1.36-5.00$

Focus on the positive

3.0

0.80

$1-5$

$1.00-4.88$

Behavioral escape-avoidance

2.3

0.55

$1-5$

$1.00-3.78$

Areas of Control

Symptom-emotion control

5.1

1.37

$1-7$

$1.00-7.00$

Relationship control

5.2

1.48

$1-7$

$1.00-7.00$

Medical care control

5.1

1.51

$1-7$

$1.00-7.00$

Disease control

4.5

1.78

$1-7$

$1.00-7.00$

Overall Adjustment

Emotional Adjustment

$143.4 \quad 45.87$

$0-216$

$32-214$

Note. Listwise deletion of observations was used to include only subjects included in the covariance structure analyses which follow.

$\underline{N}=135$ 
Table 2

Correlations among the Subscales

\begin{tabular}{|c|c|c|c|c|c|c|c|c|c|}
\hline Subscale & 2 & 3 & 4 & 5 & 6 & 7 & 8 & 9 & 10 \\
\hline 1. Seek and use social support & $.42 * *$ & $.26^{* *}$ & $.65^{* *}$ & $.48^{* *}$ & .01 & -.01 & $.24^{* *}$ & $.19^{*}$ & .12 \\
\hline 2. Cognitive escape-avoidance & - & $.34 * *$ & $.30 * *$ & $.58^{* *}$ & $-.37^{* *}$ & $-.31 * *$ & $-.28 * *$ & $-.23 * *$ & $-.31^{* *}$ \\
\hline 3. Distancing & & - & $.38 * *$ & $.31^{* *}$ & .11 & .03 & .06 & .02 & .13 \\
\hline 4. Focus on the positive & & & - & $.32^{* *}$ & $.22 *$ & $.19^{*}$ & $.29 * *$ & $.25^{* *}$ & $.36 * *$ \\
\hline 5. Behavioral escape-avoidance & & & & - & $-.36 * *$ & $-.32 * *$ & -.13 & -.07 & $-.34 * *$ \\
\hline 6. Symptom-emotion control & & & & & - & $.61^{* *}$ & $.60^{* *}$ & $.35^{* *}$ & $.54^{* *}$ \\
\hline 7. Relationship control & & & & & & - & $.47^{* *}$ & $.20^{*}$ & $.49^{* *}$ \\
\hline 8. Medical care control & & & & & & & - & $.47^{* *}$ & $.42^{* *}$ \\
\hline 9. Disease control & & & & & & & & - & $.45^{* *}$ \\
\hline 10. Emotional Adjustment & & & & & & & & & - \\
\hline
\end{tabular}

Note. Listwise deletion of observations with missing data was used so that correlations correspond to those used in the covariance structure analyses which follow. $\underline{N}=135 . * \underline{p}<.05 . * * \underline{p}<.01$. 
subscales were positively associated with one another, their correlations with the control subscales and with emotional adjustment were not all positive. The escapeavoidance coping subscales were negatively associated with the four areas of control and with emotional adjustment, while the other coping subscales were positively associated with the four areas of control and emotional adjustment. The control subscales were positively associated with one another and with emotional adjustment.

\section{Patterns of Coping}

Hypothesis 1: A sixth pattern of coping, problem-focused, will emerge when additional problem-focused coping alternatives are added to the WOC-CA inventory.

H1 was examined using the SPSS Windows 6.1 version of LISREL 7. Three confirmatory factor analyses were performed:

1. The first confirmatory factor analysis model specified six factors and included the original 49 WOC-CA items identified by Dunkel-Schetter et al. (1992) plus four additional problem-focused items written specifically for the current study.

2. A second model specified Dunkel-Schetter's original five factors but included the four new problem-focused items as well as the original 49 WOC-CA items. The four new items were included in the Social Support factor which appeared to contain several other problem-focused items (e.g., tried to get professional help, made a plan of action and followed it, tried not to close off options).

3. A third model specified five factors and was based on the 49 items included in the five patterns of coping described by Dunkel-Schetter et al. (1992).

Goodness of fit measures for the three models were relatively low (Table 3). 
Table 3

Goodness of Fit Measures for Three Confirmatory Factor Analysis Models

\begin{tabular}{|c|c|c|c|}
\hline & 6-Factor Model & $\begin{array}{c}\text { 5-Factor Model with } \\
\text { New Items }\end{array}$ & $\begin{array}{c}\text { 5-Factor Model } \\
\text { without New Items }\end{array}$ \\
\hline $\mathrm{X}^{2}$ & $3,001.11$ & $3,032.00$ & $2,508.11$ \\
\hline $\mathrm{df}$ & 1,362 & 1,367 & 1,117 \\
\hline GFI & .590 & .587 & .605 \\
\hline AGFI & .553 & .551 & .567 \\
\hline RMSR & .159 & .160 & .164 \\
\hline \multicolumn{4}{|c|}{ Note. GFI=Goodness of Fit Index; AGFI=Adjusted Goodness of Fit Index; } \\
\hline \multicolumn{4}{|c|}{ RMSR=Root Mean Square Residual. } \\
\hline
\end{tabular}

None of the models appeared to fit the data substantially better than any of the other models. All of the factor loadings in the three models were significantly greater than zero $(t>2.0)$. Thus, on the basis of fit alone, it did not appear that a six-factor solution was better than the original five-factor solution.

Table 4 displays the interfactor correlations for the six-factor solution. The correlations between Problem Focused and Social Support (.92) and between Problem Focused and Focus on the Positive (.88) were quite high. The Problem Focused factor was not sufficiently distinct to warrant its inclusion in further analyses. Thus, H1 was not supported. 
Table 4

$\underline{\text { Six-Factor Model - Interfactor Correlations }}$

\begin{tabular}{lcccccc}
\hline \multicolumn{1}{c}{ Factor } & 1 & 2 & 3 & 4 & 5 & 6 \\
\hline & & & & & & \\
1. Seek and use social support & - & .92 & .64 & .43 & .78 & .65 \\
2. Problem focused & & - & .63 & .67 & .88 & .67 \\
3. Cognitive escape-avoidance & & - & .56 & .51 & .82 \\
4. Distancing & & & - & .64 & .42 \\
5. Focus on the positive & & & & - & .52 \\
6. Behavioral escape-avoidance & & & & & - \\
\end{tabular}

Note. All correlations are significant, $\mathfrak{p}<.05$.

$\underline{N}=185$

All subsequent analyses that included patterns of coping were based on the original five-factor solution identified by Dunkel-Schetter et. al (1992). The factor loadings obtained in the current study and those reported by Dunkel-Schetter are displayed in Table 5. The interfactor correlations for the five-factor model ranged from .51 to .82 , indicating strong relationships among the factors (Table 6). 
Table 5

Coping Factors Derived from WOC-CA

Scale/Item Description

Talked to someone to find out more

Factor Dunkel-Schetter

Talked to someone about how feeling Loading Factor Loading

Talked to someone who could do something

Let my feelings out somehow

Tried to get professional help

Tried to find out as much as I could .58

Looked for sympathy or understanding

Asked a friend or relative for advice

Tried not to close off options

Made a plan of action and followed it

Concentrated on the next step

\section{Cognitive Escape-avoidance ${ }^{b}$}

Hoped a miracle would happen

Prayed

Prepared for the worst

Wished the situation would go away or be over

Had fantasies/wishes about how it might turn out

Went over in my mind what I would say or do

Went along with fate

Depended mostly on others to handle things

Slept more than usual

\section{Distancinge}

Tried to keep my feelings from interfering $\quad .50$

Didn't let it get to me; refused to think about it

Made light of it; refused to get too serious

Went on as if it were not happening

Tried to keep my feelings to myself

Looked for silver lining, looked on the bright side

Treated the illness as a challenge

Knew what had to be done so increased efforts

Tried to forget the whole thing

Kept others from knowing how bad things were

Reminded myself how much worse things could be 
Table 5 (continued)

Coping Factors Derived from WOC-CA

\begin{tabular}{lcc} 
& Factor & Dunkel-Schetter \\
Scale/Item Description & Loading & Factor Loading \\
\hline
\end{tabular}

Focus on the Positive ${ }^{d}$

$\begin{array}{lll}\text { Found new faith } & .56 & .77\end{array}$

Rediscovered what is important in life $\quad .64 \quad 71$

$\begin{array}{lll}\text { Changed or grew as a person in a good way } & .77 & .70\end{array}$

$\begin{array}{lll}\text { Changed something about myself } & .76 & .62\end{array}$

Came out of the experience better than before $\quad .70 \quad .57$

Changed something so things will turn out $\quad .65 \quad .57$

$\begin{array}{lll}\text { Was inspired to be creative } & .56 & .39\end{array}$

$\begin{array}{lll}\text { Thought of how a person I admire would act } & .44 & .35\end{array}$

\section{Behavioral Escape-Avoidance ${ }^{e}$}

$\begin{array}{lll}\text { Avoided being with people } & .53 & .62\end{array}$

Tried to make myself feel better by eating, drinking, $\quad .31 \quad .57$

smoking, or using drugs

$\begin{array}{lll}\text { Took a big chance and did something risky } & .55 & .55\end{array}$

Took it out on other people $\quad .64 \quad .33$

Came up with different solutions $\quad .46 \quad .43$

Waited to see what would happen before acting $\quad .45 \quad 45$

$\begin{array}{lll}\text { Criticized or lectured myself } & .30 & .34\end{array}$

Did something just to do something $\quad .63 \quad .26$

$\begin{array}{lll}\text { Tried not to act too hastily } & .38 & .26\end{array}$

${ }^{\mathrm{a} A l p h a}=.87 .{ }^{\mathrm{b}} \mathrm{Alpha}=.73 .{ }^{\mathrm{C}} \mathrm{Alpha}=.77 .{ }^{\mathrm{d}} \mathrm{Alpha}=.84 .{ }^{\mathrm{e}} \mathrm{Alpha}=.72 \mathrm{.}$ 
Table 6

Five-Factor Model Excluding New Items - Interfactor Correlations

\begin{tabular}{llllll}
\hline \multicolumn{1}{c}{ Factor } & 1 & 2 & 3 & 4 & 5 \\
\hline & & & & & \\
1. Seek and use social support & - & .66 & .51 & .81 & .65 \\
2. Cognitive escape-avoidance & & - & .55 & .51 & .82 \\
3. Distancing & & - & .64 & .41 \\
4. Focus on the positive & & & - & .51 \\
5. Behavioral escape-avoidance & & & & - \\
\hline
\end{tabular}

Note: All correlations are significant, $\underline{p}<.05$.

$\underline{N}=185$

\section{Perceived Control and Emotional Adjustment}

Hypothesis 2: Perceptions of symptom-emotion control will have a greater influence on emotional adjustment than will perceptions of disease control.

As a first step in examining $\mathrm{H} 2$, the hypothesis that the correlation of symptomemotion control with emotional adjustment was equal to the correlation of disease control with emotional adjustment was tested. Contrary to expectations, the zero-order correlation between symptom-emotion control and emotional adjustment (.54) was not significantly greater than the correlation between disease control and emotional adjustment $(.45), \underline{t}(134)=1.15, \underline{p}>.05$.

Hierarchical regression results predicting adjustment from the four areas of control are presented in Table 7. The areas of control were entered in two steps. 
Table 7

Hierarchical Regression Results Predicting Adjustment from Four Areas of Control

\begin{tabular}{|c|c|c|c|c|c|}
\hline \multirow[b]{2}{*}{ Step/Variable } & \multicolumn{3}{|c|}{ Adjusted } & \multirow{2}{*}{$\begin{array}{c}\underline{\mathbf{R}}^{2} \\
\text { Increment }\end{array}$} & \multirow{2}{*}{$\begin{array}{c}\underline{\mathbf{F}} \\
\text { Increment }\end{array}$} \\
\hline & $\underline{\mathrm{R}}^{2}$ & $\underline{\mathrm{R}}^{2}$ & $\underline{\mathbf{F}}$ & & \\
\hline 1. Disease control & .201 & .195 & $33.98^{*}$ & & \\
\hline 2. Control of consequences & .413 & .395 & $23.23^{*}$ & .212 & $15.89^{*}$ \\
\hline \multicolumn{6}{|c|}{ Note: Control of consequences = symptom-emotion control, relationship control, and } \\
\hline \multicolumn{6}{|c|}{ medical care control. ${ }^{*} \mathrm{p}<.001$} \\
\hline$\underline{N}=137$ & & & & & \\
\hline
\end{tabular}

Disease control was entered at step 1. Control of the consequences of the cancer (i.e., symptom-emotion, relationship, and medical care control) was entered at step 2.

Disease control explained $20.1 \%$ of the variance in adjustment scores. When control of the consequences was entered at step 2 , an additional $21.2 \%$ of the variance in emotional adjustment was explained. Examination of the regression coefficients revealed substantial multicollinearity among the variables (see Table 8). Although all four areas of control were substantially correlated with emotional adjustment, only disease control, symptom-emotion control, and relationship control had significant regression coefficients. After controlling for the other variables, medical care control did not explain any of the variance in emotional adjustment. 
Table 8

Regression Coefficients Predicting Adjustment from Four Areas of Control

\begin{tabular}{|c|c|c|c|c|c|c|}
\hline & & & & Semi- & & \\
\hline Variable & $\underline{\mathrm{B}}$ & Beta & Simple $\underline{\mathrm{r}}$ & partial $\underline{\underline{r}}$ & $\underline{t}$ & p \\
\hline Disease control & 7.80 & .30 & .45 & .26 & 3.96 & .0001 \\
\hline Symptom-emotion control & 9.23 & .27 & .54 & .19 & 2.89 & .0046 \\
\hline Relationship control & 8.29 & .27 & .49 & .21 & 3.16 & .0020 \\
\hline Medical care control & -0.25 & -.01 & .43 & -.01 & -0.09 & .9289 \\
\hline (Constant) & 19.64 & & & & & \\
\hline
\end{tabular}

Since there was a high degree of multicollinearity among the areas of control, a regression model including only disease control and symptom-emotion control was examined. Results appear in Table 9. The semi-partial correlations show that after controlling for symptom-emotion control, disease control explained 7.5\% (semi-partial $\underline{\mathrm{r}}=.27, \underline{\mathrm{p}}<.001)$ of the total variance in adjustment. In contrast, symptom-emotion control explained $16.6 \%$ (semi-partial $\underline{\underline{r}}=.41, \mathfrak{p}<.001)$ of the total variance in adjustment after partialing out disease control. 
Table 9

Regression Coefficients and Semi-Partial Correlations Predicting

Adjustment from Disease Control and Symptom-Emotion Control

\begin{tabular}{|c|c|c|c|c|c|}
\hline \multirow[b]{2}{*}{ Variable } & \multicolumn{5}{|c|}{ Semi- } \\
\hline & $\underline{B}$ & Beta & partial $\underline{r}$ & $\underline{t}$ & $\underline{p}$ \\
\hline Disease control & 7.59 & .29 & .27 & 4.00 & .0001 \\
\hline Symptom-emotion control & 14.69 & .44 & .41 & 5.94 & .0000 \\
\hline (Constant) & 34.86 & & & & \\
\hline Note. $\underline{\mathrm{R}}^{2}=.367$, Adjusted & $=.35$ & $(2,1$ & $=38.96$ & $<.00$ & \\
\hline$\underline{N}=137$ & & & & & \\
\hline
\end{tabular}

Since Thompson and associates (1993) compared the partial correlations of the four areas of control with measures of maladjustment controlling for outcomes being achieved, an additional analysis was conducted to examine the influences of the four areas of control on emotional adjustment controlling for health status. Although Thompson used marital satisfaction and physical functioning to control for differential outcomes, it was felt that health status as reported by the patient would also reflect differential outcomes. Health status was measured on a four-point scale and subsequently dummy coded into three groups (two variables); poor/fair, good, and excellent. The partial correlations of symptom-emotion control, relationship control, 
medical care control, and disease control with emotional adjustment after partialing out the effects of health status were $.46, .40, .27$, and .28 , respectively. Consistent with Thompson's findings, after controlling for outcomes being achieved, the correlation between symptom-emotion control and adjustment was substantially greater than the correlation between disease control and adjustment. Hierarchical regression results predicting emotional adjustment from the four areas of control after partialing out the effects of health status are displayed in Tables 10 and 11. After controlling for health status, the four areas of control explain an additional $17 \%$ of the variance in emotional adjustment. The standardized regression coefficients indicated that symptom-emotion control (.26) tended to be of greater importance than disease control (.18) in predicting emotional adjustment after controlling for health status.

Table 10

Hierarchical Regression Results Predicting Adjustment from Four Areas of Control after Partialing out the Effects of Health Status

$$
\underline{\mathrm{R}}^{2} \quad \underline{\mathrm{F}}
$$

\begin{tabular}{lccccc} 
Step/Variable & $\underline{\mathrm{R}}^{2}$ & Adjusted $\underline{\mathrm{R}}^{2}$ & $\underline{\mathrm{F}}$ & Increment & Increment \\
\hline 1. Health status & .383 & .374 & $41.36^{*}$ & & \\
2. Areas of control & .554 & .533 & $26.69^{*}$ & .170 & $12.31^{*}$ \\
\hline
\end{tabular}

Note. Health status was dummy coded into three groups (two variables); poor/fair, good, and excellent. Areas of control = symptom-emotion, relationship, medical care, and disease control. ${ }^{*} \underline{\mathrm{p}}<.001 . \underline{\mathrm{N}}=136$ 
Table 11

$\underline{\text { Regression Coefficients Predicting Adjustment from Four Areas of Control after }}$ Partialing out the Effects of Health Status

\begin{tabular}{lcccc}
\hline Variable & $\underline{\mathrm{B}}$ & $\underline{\text { Beta }}$ & $\underline{\mathrm{t}}$ & $\underline{\mathrm{p}}$ \\
\hline Health1 & -60.69 & -.54 & -6.37 & .000 \\
Health2 & -28.23 & -.30 & -3.91 & .000 \\
Symptom-emotion control & 8.93 & .26 & 3.16 & .002 \\
Relationship control & 5.94 & .19 & 2.53 & .013 \\
Medical care control & -2.14 & -.07 & -0.87 & .388 \\
Disease control & 4.73 & .18 & 2.58 & .011 \\
(Constant) & 5.37 & & & \\
\hline
\end{tabular}

Note. Health status was dummy coded with Health $1=1$ for poor $/$ fair, Health2 $=1$ for good, and excellent as the control. $\underline{\mathrm{N}}=136$

Coping, Perceived Control, and Emotional Adjustment

Hypothesis 3: The relationship between coping and emotional adjustment will be mediated by perceived control.

Planned analyses included using the five patterns of coping as indicators of a latent variable representing coping, and the four areas of control as indicators of a latent variable representing perceived control. The objective was to examine the hypothesis that perceived control mediates the relationship between coping and adjustment by comparing the fit of three models: 


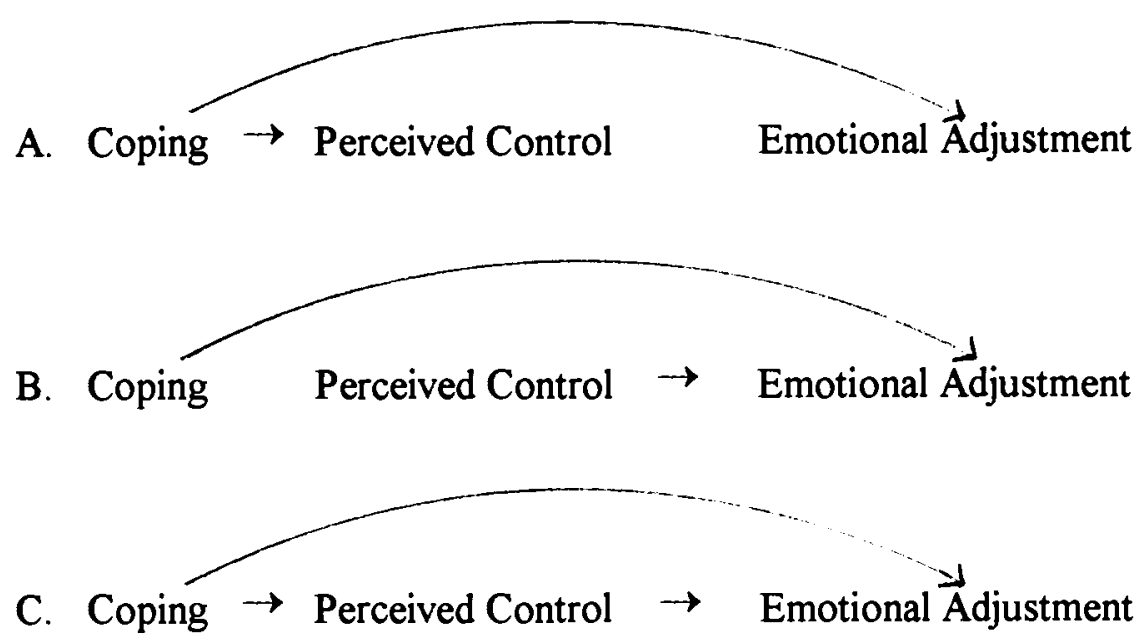

To establish that a variable operates as a mediator, the following relationships must exist (Baron \& Kenny, 1986):

1. The independent variable (coping) should explain significant amounts of the variation in both the dependent variable (emotional adjustment) and the proposed mediator variable (perceived control). Thus, the paths in Model A should be significant.

2. Both the independent variable (coping) and the proposed mediator (perceived control) should explain significant amounts of the variation in the dependent variable (emotional adjustment). Thus, the paths in model B should be significant.

3. Further, when a path from the independent variable (coping) to the mediator variable (perceived control) is added to Model B to create Model C, the existing path from the independent variable to the dependent variable should become nonsignificant, or substantially reduced.

In addition to examining the path coefficients, covariance structure modeling 
(CSM) permits the comparison of the goodness of fit of models provided that one of the models to be compared is fully nested within the other model. Since Models A and B are completely nested within Model $C$, each can be compared to Model C using a $\chi^{2}$ difference test. If Model $\mathrm{C}$ fits the data significantly better than Model $\mathrm{A}$ and the coefficients for the paths leading from coping to perceived control and from perceived control to emotional adjustment are significant, we can conclude that perceived control mediates the relationship between coping and emotional adjustment. If Model B fits the data better than Model $C$ and the paths from coping and perceived control to emotional adjustment are significant, it can be concluded that coping and perceived control exert separate influences on adjustment.

Contrary to expectations, the models in which the five patterns of coping were used as indicators of one coping latent variable were not helpful in understanding the relationships among coping, perceived control, and emotional adjustment. Despite the significant correlations among many of the coping patterns and the four areas of control and adjustment, the coping latent variable was not predictive of perceived control or of emotional adjustment. The path coefficients for coping to perceived control $(\gamma=.06, \underline{t}$ $=.55)$ and for coping to adjustment $(\gamma=.10, \mathrm{t}=1.08)$ in Model $\mathrm{A}$ were not significant. In an effort to understand why the coping latent variable was not useful, the relationships among the coping variables and the control variables and among the coping variables and adjustment were further explored.

Canonical correlation was used to examine the relationship between the set of coping variables and the set of control variables. Although the coping latent variable 
from CSM was not predictive of perceived control, a canonical correlation of .63 indicates that $39 \%$ of the variance in the set of control variables was explained by the

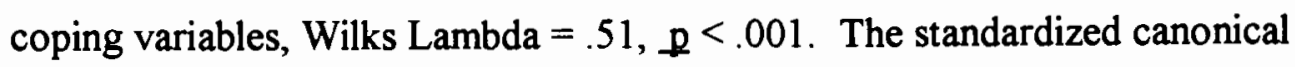
coefficients (see Table 12) indicated that high use of cognitive and behavioral escapeavoidance and low use of focus on the positive were associated with lack of control, as indicated by the negative coefficient for the four areas of control. While there are mixed signs on the standardized coefficients for the coping variables calculated in the canonical correlation procedure, all of the factor loadings for the indicators of coping in the CSM were positive. Thus, it appears that the relationship between coping and

Table 12

Canonical Correlation of Coping Variables with Control Variables

Standardized

Standardized

Coping Variables

Coefficients

Control Variables

Coefficients

Social support

$-.28$

Symptom-emotion

$-.39$

Cognitive escape-avoidance .73

Relationship

$-.32$

Distancing

$-.18$

Medical care

$-.31$

Focus on the positive

$-.56$

Disease

$-.26$

Behavioral escape-avoidance

.40

Note. Canonical $\underline{\mathrm{R}}=.63$. Wilks Lambda $=.51, \underline{\mathrm{E}}(20,445)=4.96, \underline{\mathfrak{p}}<.001$. 
perceived control may be driven by the unique variance in each of the coping patterns rather than by their shared variance as represented by a single latent variable.

Evidence that it is the unique variance among the patterns of coping rather than their shared variance that is of greater importance in predicting emotional adjustment is contained in an examination of the semi-partial correlations of the five patterns of coping with adjustment. When the five patterns of coping were entered into a regression model to predict adjustment, $42.5 \%$ of the variance in adjustment was explained by the coping patterns. The sum of the squared semi-partial correlations between each of the coping patterns and adjustment while controlling for the other coping patterns provides a measure of the unique contribution of the coping patterns to explanation of the variance in emotional adjustment scores. Of the total amount of variance explained, $67 \%$ was explained by the unique contributions of each of the coping patterns, while the shared contribution of the coping patterns was only $33 \%$ (see Table 13).

In order not to lose the unique contribution of each of the coping patterns to the explanation of the variance in emotional adjustment, the five coping patterns were used as perfect indicators of five coping variables (see Figure 1). Thus, the analyses which follow are identical to the planned analyses outlined above except that five coping variables are used instead of one. The standardized coefficients for the paths estimated in Models A, B, and C (Figures 2-4) indicate that the criteria for a mediated relationship were met for three of the coping variables and adjustment: 
Table 13

Semi-Partial Correlations for Each of the Patterns of Coping with Adjustment while Controlling for the Other Patterns of Coping and Variance Explained Predicting Adjustment from Patterns of Coping

Social support

Cognitive escape-avoidance

Focus on the positive

Behavioral escape-avoidance

Total
Distancing

.067

$-.239 *$

$.135^{*}$

$.335^{*}$

$-.309^{*}$

.095

.286

Variance Explained

Total variance explained $\left(\underline{R}^{2}\right)$ .425

.286

139

.004

.057

.018

.112

Percent of Total Variance

100.0

Unique variance

67.3

Shared variance

$\underline{N}=135{ }^{*} \underline{p}<.05$ 


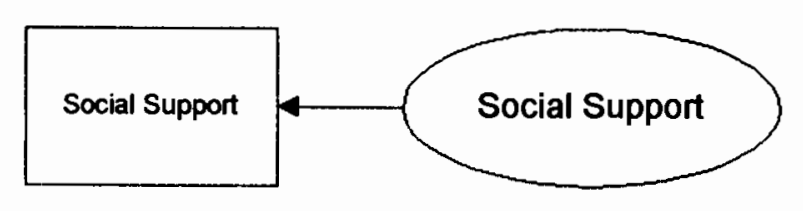

\section{Figure 1}

Measurement Model: Patterns of Coping, Perceived

Control, and Emotional Adjustment
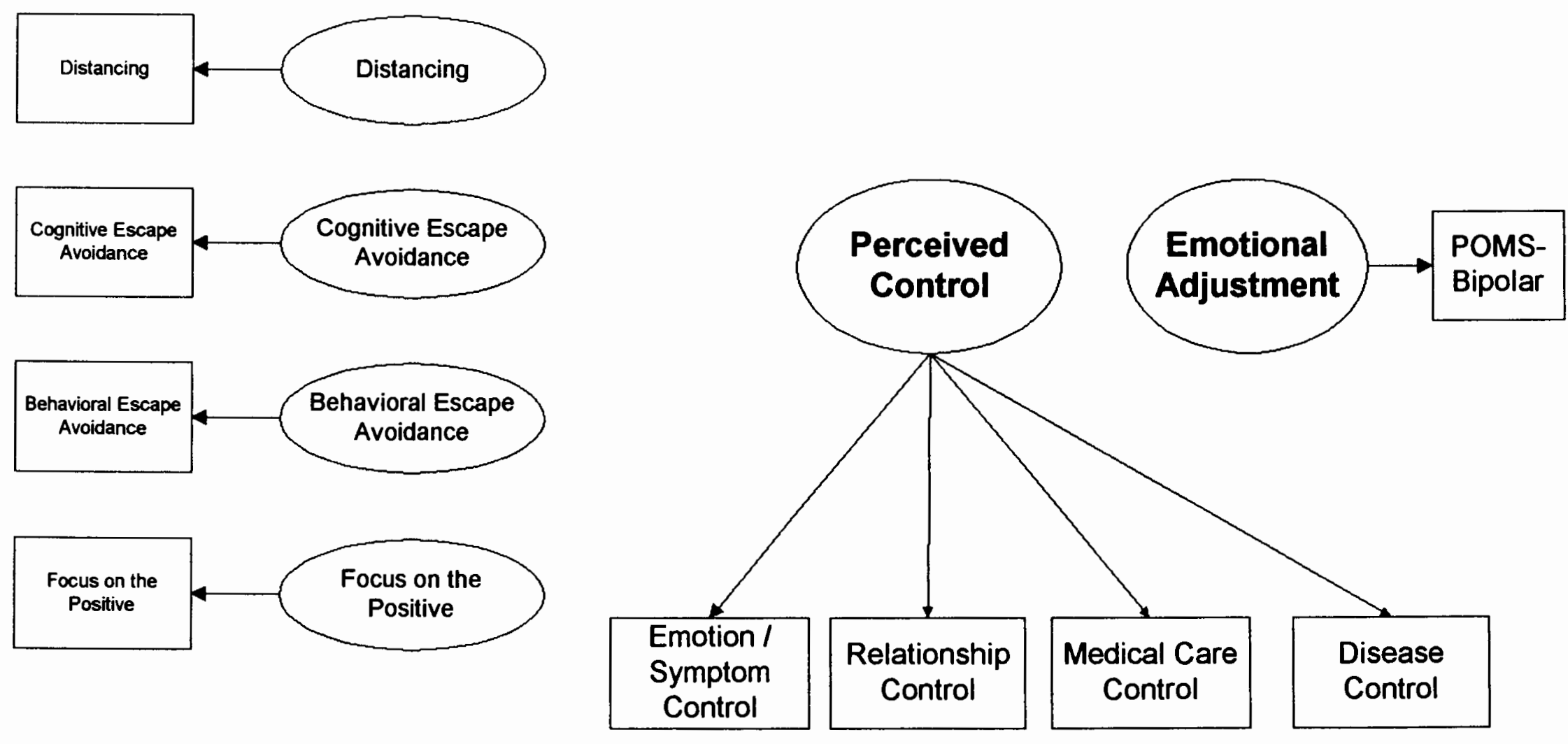

Control 


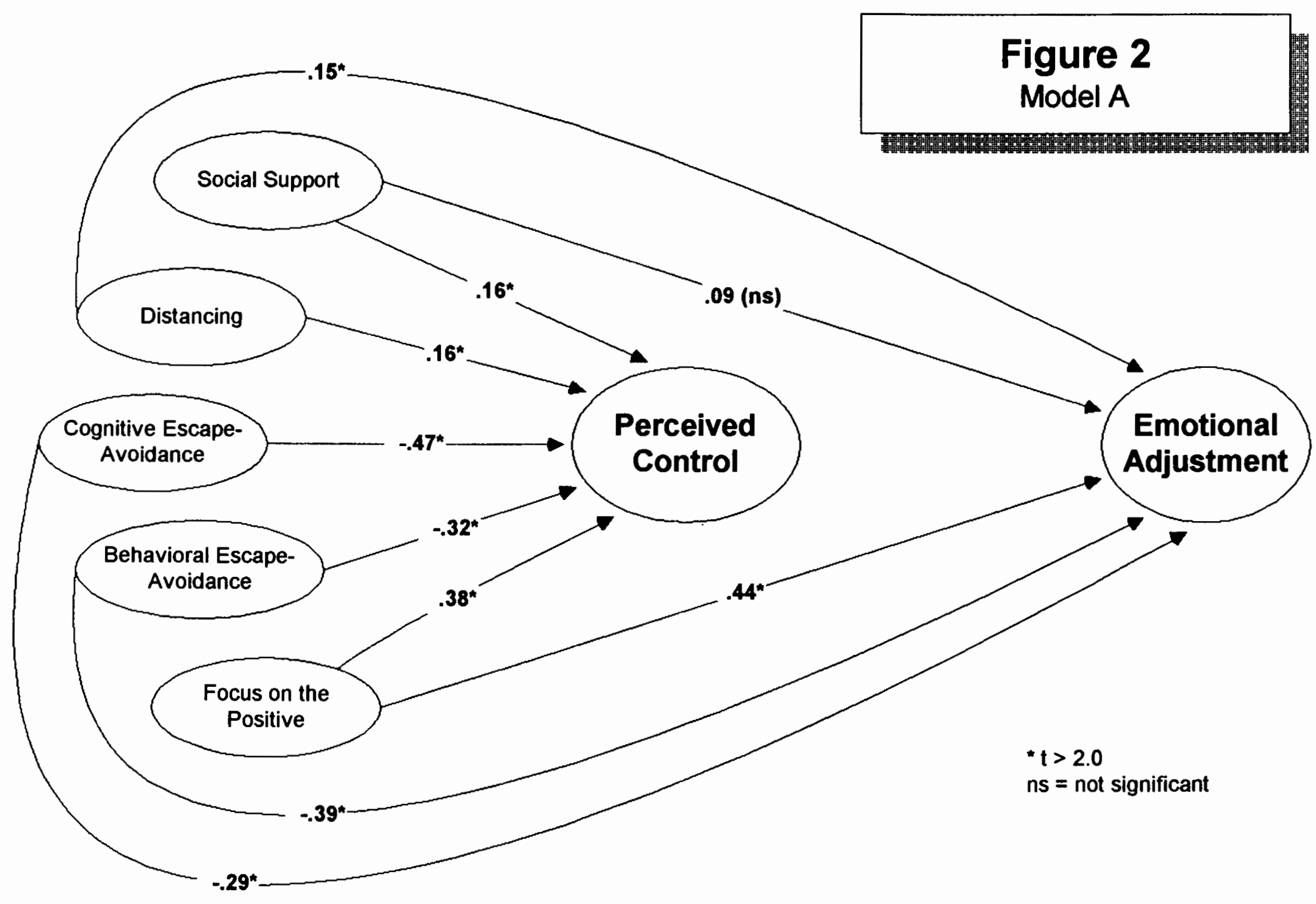




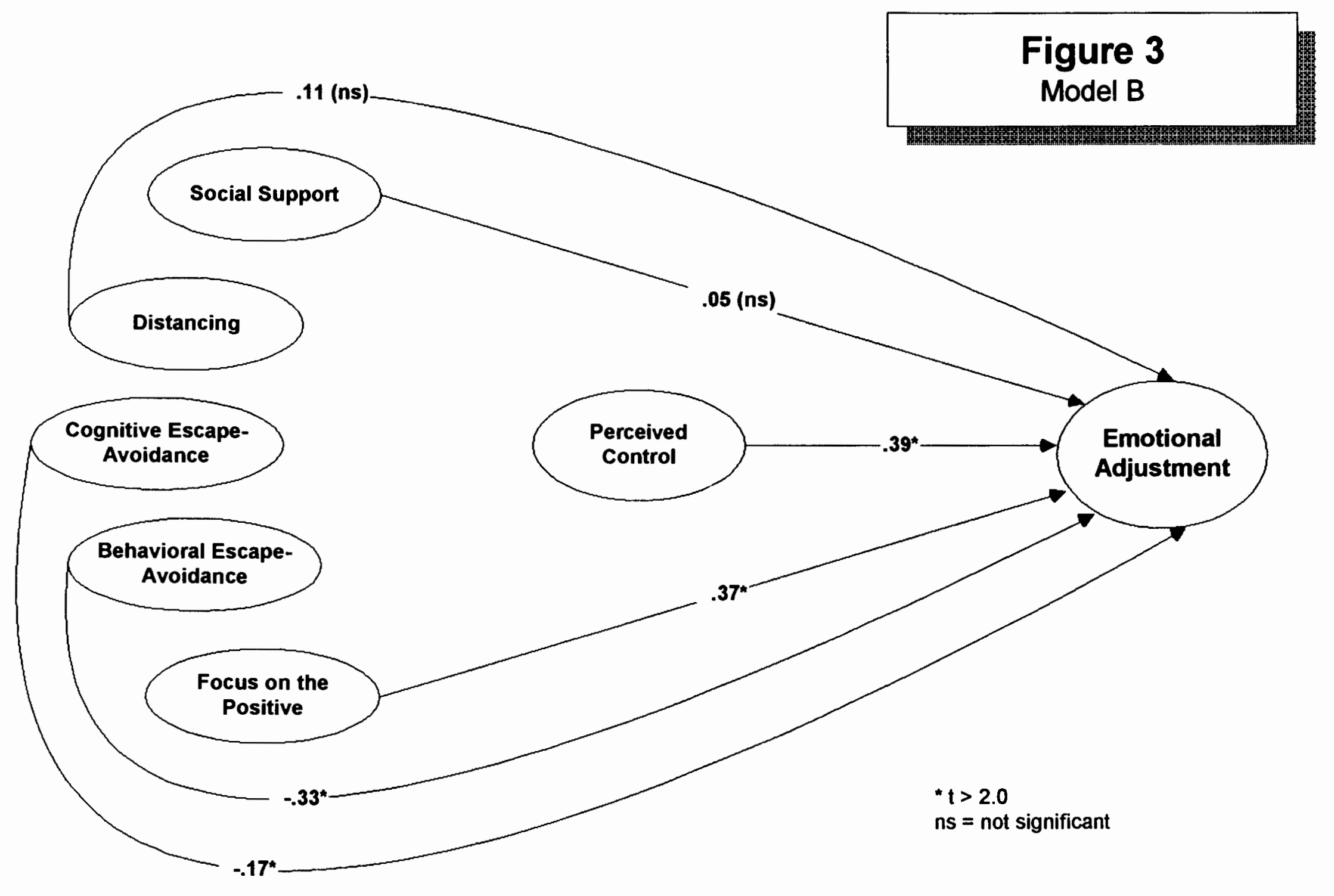




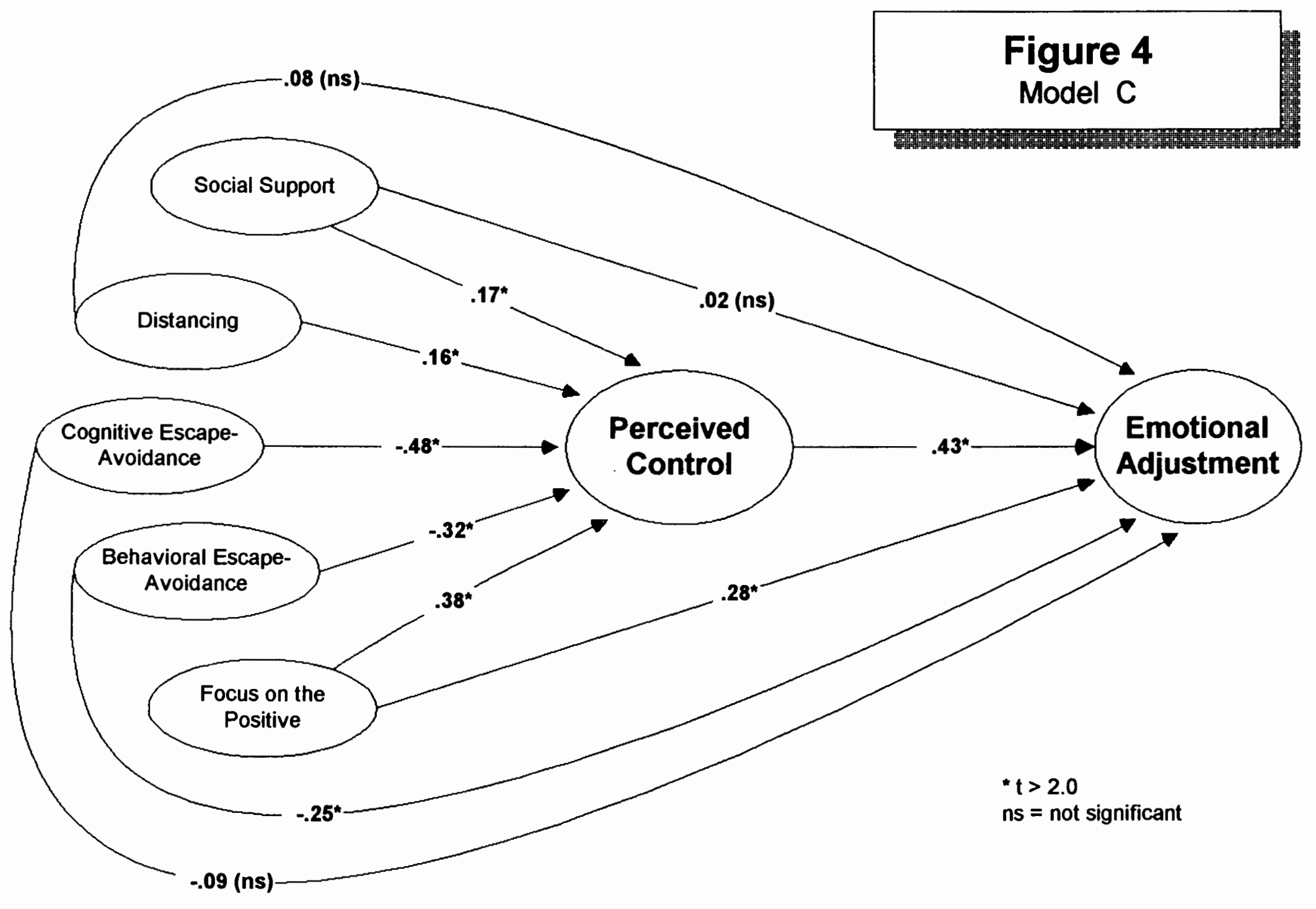


1. Model A in Figure 2 shows that with the exception of social support, the independent variables explained significant amounts of the variation in both emotional adjustment and perceived control. With the exception of the path from social support to emotional adjustment, all of the paths were significant, $t>2.0$. The paths from the five coping variables to perceived control are consistent with the standardized canonical correlation coefficients except that the signs were reversed in the canonical analysis. Social support, distancing, and focus on the positive were positively associated with perceived control, while cognitive and behavioral avoidance had inverse relationships with perceived control.

2. Model B, Figure 3, shows that three of the independent variables (cognitive escape-avoidance, behavioral escape-avoidance, and focus on the positive) and the proposed mediator (perceived control) explained significant amounts of the variation in the dependent variable (emotional adjustment). The paths from social support and distancing, however, were not significant.

3. Model C, Figure 4, shows that when a path from perceived control to emotional adjustment was added to Model A to form Model C, the paths from cognitive escape-avoidance, behavioral escape-avoidance, and focus on the positive to emotional adjustment were substantially reduced. The path from cognitive escape-avoidance to emotional adjustment became nonsignificant with the addition of the path from perceived control to emotional adjustment. The paths from behavioral escapeavoidance and focus on the positive declined from -.39 to -.25 and from .44 to .28 , respectively (Table 14). 
Table 14

Path Coefficients for Models A, B, and C

\begin{tabular}{llll}
\hline Paths & Model A & Model B & Model C \\
\hline
\end{tabular}

From Coping Patterns to

Perceived Control

Social support

$\begin{array}{lc}.16^{*} & .17^{*} \\ .16^{*} & .16^{*} \\ -.47^{*} & -.48^{*} \\ -.32^{*} & -.32^{*} \\ .38^{*} & .38^{*}\end{array}$

Distancing

Cognitive escape-avoidance

Behavioral escape-avoidance

Focus on the positive Model B

From Coping Patterns to

Emotional Adjustment

Social support

$$
.09
$$

.05

.02

Distancing

$.15^{*}$

.11

.08

Cognitive escape-avoidance

$-.29 *$

$-.17^{*}$

$-.09$

Behavioral escape-avoidance

$-.39 *$

$-.33^{*}$

$-.25 *$

Focus on the positive

$.44^{*}$

$.37^{*}$

$.28^{*}$

From Perceived Control to

Emotional Adjustment 
Taken together, these findings provide partial support for the hypothesis that perceived control mediates the relationship between coping and emotional adjustment. However, only the relationship between cognitive escape-avoidance and emotional adjustment was fully mediated by perceived control. Behavioral escape-avoidance and focus on the positive had both indirect (mediated) and direct influences on emotional adjustment. Social support and distancing appeared to affect perceived control but not emotional adjustment. Comparisons of the fit of Models A, B, and C also suggest that a mediator relationship exists (see Table 15). As expected, Model C fit the data significantly better than Models A or B. It should be noted, however, that goodness of fit measures for all three models were relatively low.

Factor loadings and squared multiple correlations for the four areas of control are presented for Model $\mathrm{C}$ in Table 15. Since the factor loadings and variance accounted for by the latent variable for the other models are similar, only the loadings for Model C have been presented. Based on Model C, the coping variables explained $52.6 \%$ of the variance in perceived control. The coping variables and perceived control explained $55.2 \%$ of the variance in emotional adjustment.

Three additional models were estimated to examine the possibility that the coping variables mediate the relationship between perceived control and emotional adjustment (see Figures 5 - 7). Although this was not the expected relationship, these models were included to acknowledge that a more traditional view such as that presented by Folkman (1984) may describe the relationships among coping, control, and adjustment. Since Models D, E, and F are not nested within any of the previous 
Table 15

Measures of Fit - Perceived Control as Mediator

\begin{tabular}{lccccccc}
\hline \multicolumn{1}{c}{ Model } & $\chi^{2}$ & df & $\chi_{\text {difference }}^{2}$ & df & GFI & AGFI & RMSR \\
\hline & & & & & & & \\
Model A & 264.68 & 31 & $16.03^{*}$ & 1 & .689 & .448 & 21.29 \\
Model B & 317.58 & 35 & $68.93^{*}$ & 5 & .665 & .474 & 38.23 \\
Model C & 248.65 & 30 & & & .698 & .446 & 21.14
\end{tabular}

Note. $\chi_{\text {difference }}^{2}$ reflects comparisons to Model C. GFI $=$ Goodness of Fit

Index. $\mathrm{AGFI}=$ Adjusted Goodness of Fit Index. $\mathrm{RMSR}=$ Root Mean

Square Residual.

$* \mathfrak{p}<.01$

Table 16

Factor Loadings and Squared Multiple Correlations for Model C

\begin{tabular}{lcc}
\hline Areas of Control & Lambda y & $\underline{\mathrm{R}}^{2}$ \\
\hline & & \\
Symptom-emotion control & .841 & .708 \\
Relationship control & .702 & .492 \\
Medical care control & .734 & .539 \\
Disease control & .507 & .257 \\
\hline
\end{tabular}




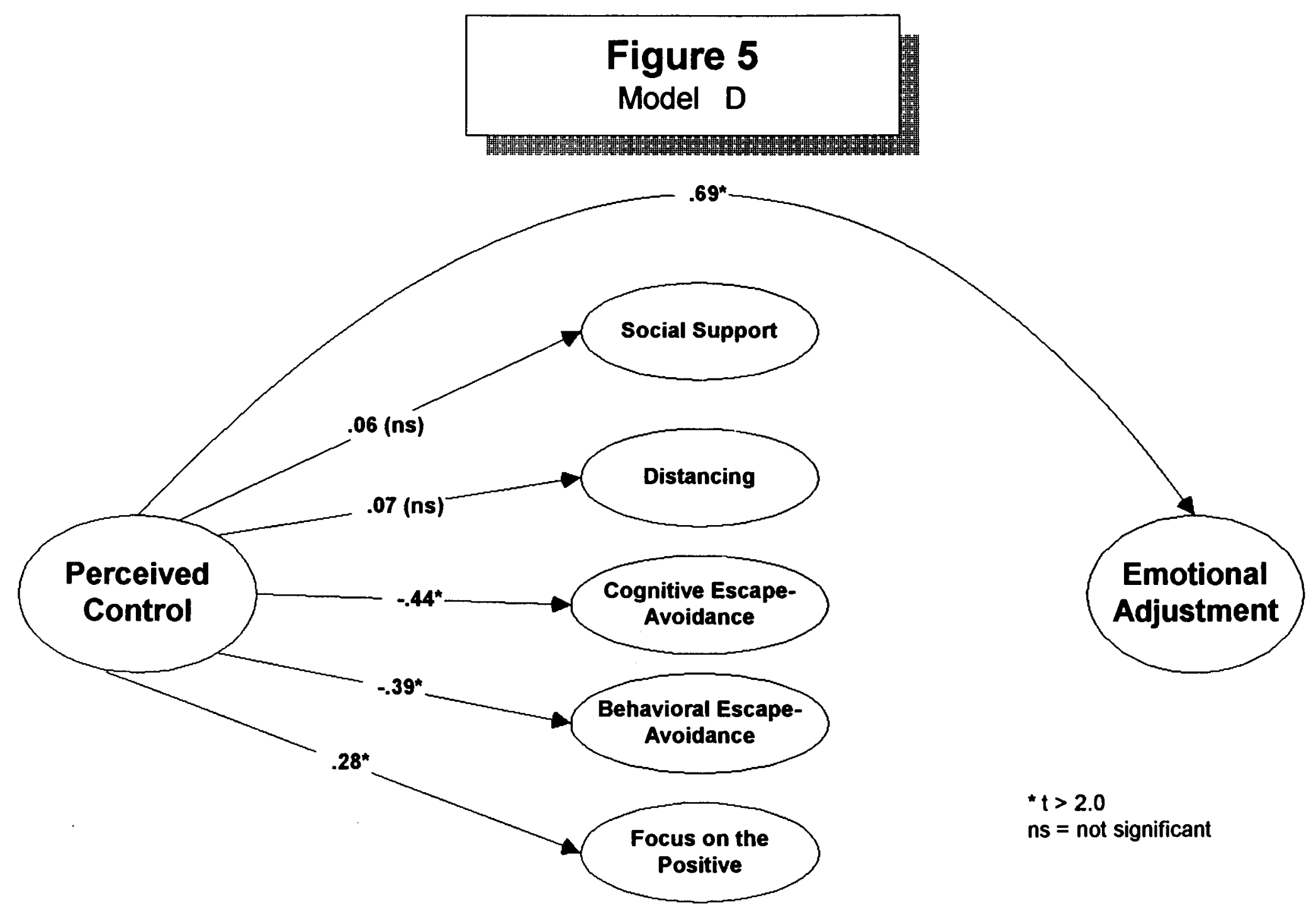




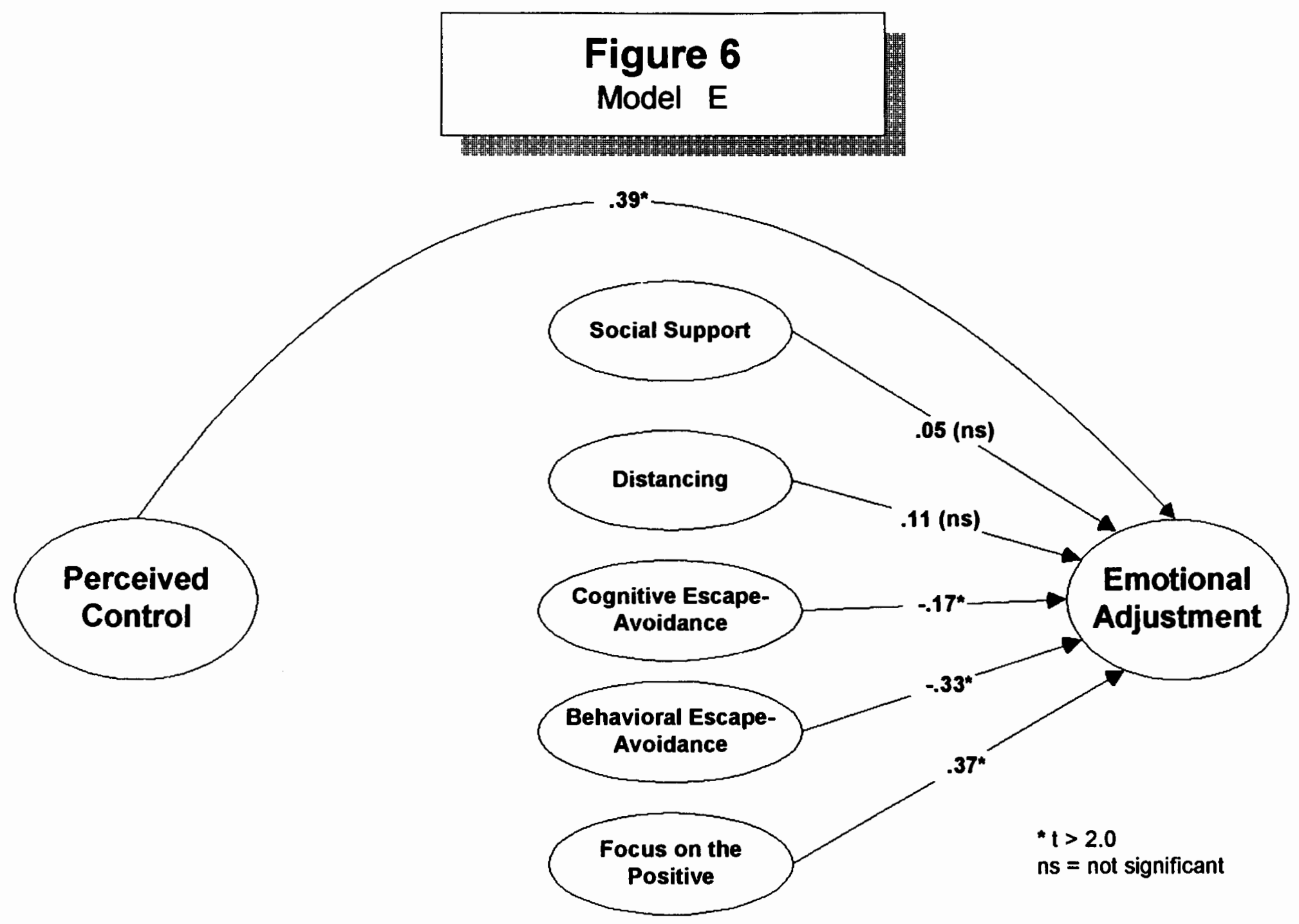




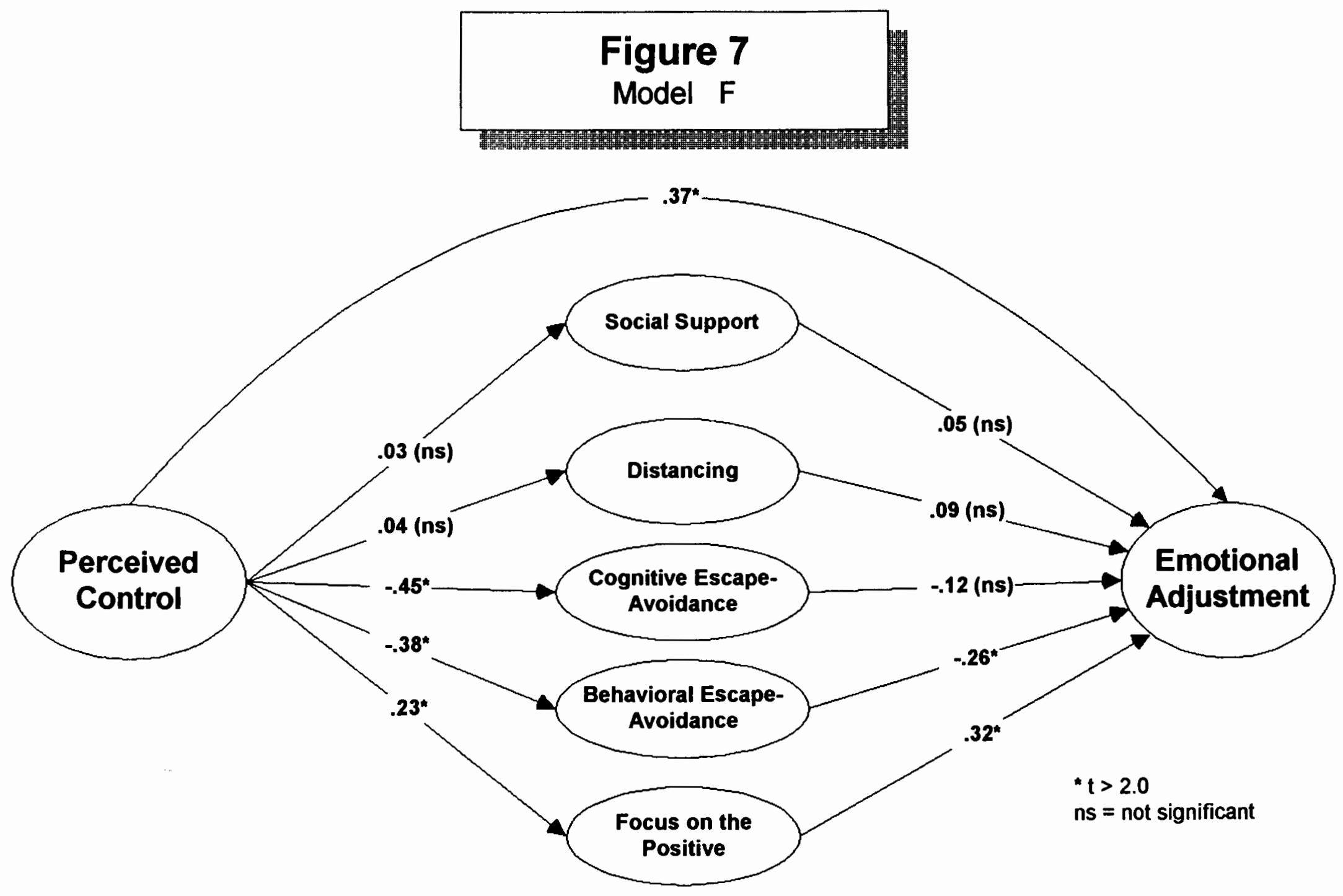


models, they cannot be statistically compared to Models A, B, and C. However, Models D and E can be compared to Model F.

Three of the coping patterns may act as mediators between perceived control and emotional adjustment. The criteria for mediation outlined by Baron and Kenny (1986) were met for cognitive escape-avoidance, behavioral escape-avoidance, and focus on the positive:

1. Perceived Control explained significant amounts of the variation in cognitive escape-avoidance, behavioral escape-avoidance, and focus on the positive as well as in the dependent variable, emotional adjustment (see Figure 5) as indicated by the significant paths.

2. Perceived control, cognitive escape-avoidance, and behavioral escapeavoidance explained significant amounts of variance in emotional adjustment (see Figure 6). It is interesting to note that with the addition of the paths from the coping patterns to emotional adjustment, the path coefficient from perceived control to emotional adjustment was reduced from .69 to .39 . This reduction occurred prior to the addition of paths which would have permitted a mediated relationship between perceived control and adjustment.

3. When paths from perceived control to the five coping patterns were added to Model D to create Model F (see Figure 7), the direct relationship between perceived control and emotional adjustment was substantially reduced, from a coefficient of .69 to .37 (Table 17). 
Table 17

Path Coefficients for Models D, E, and F

\begin{tabular}{llll}
\hline Paths & Model D & Model E & Model F \\
\hline
\end{tabular}

From Perceived Control to

Coping Patterns

Social support .06

Distancing

Cognitive escape-avoidance

Behavioral escape-avoidance

Focus on the positive

From Perceived Control to

Emotional Adjustment

\section{From Coping Patterns to}

Emotional Adjustment

Social support

$$
.05
$$

Distancing

.11

.09

Cognitive escape-avoidance

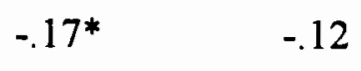

Behavioral escape-avoidance 
Further, examination of the $\chi_{\text {difference }}^{2}$ statistic indicates that Model F fits the data better than Models D and E (see Table 18). Thus, it could be argued that cognitive escape-avoidance, behavioral escape-avoidance, and focus on the positive may act as mediators between perceived control and emotional adjustment. However, it should be noted again that the reduction in the coefficient for the path from perceived control to emotional adjustment occurred when the coping variables were introduced as predictors

Table 18

Measures of Fit - Coping Patterns as Mediators

\begin{tabular}{lccccccc}
\hline Model & $\chi^{2}$ & df & $\chi_{\text {difference }}^{2}$ & df & GFI & AGFI & RMSR \\
\hline & & & & & & & \\
Model D & 292.60 & 35 & $23.85^{*}$ & 5 & .647 & .446 & 1.74 \\
Model E & 317.58 & 35 & $48.83^{*}$ & 5 & .665 & .474 & 38.23 \\
Model F & 268.75 & 30 & & & .661 & .378 & 22.00
\end{tabular}

Note. $\chi_{\text {difference }}^{2}$ reflects comparisons to Model F. GFI $=$ Goodness of Fit

Index. $\quad$ AGFI $=$ Adjusted Goodness of Fit Index. RMSR $=$ Root Mean

Square Residual.

$* \mathrm{p}<.01$ 
Coping and Control 63

of emotional adjustment rather than when the mediational paths were added in Model $\mathrm{F}$ which weakens the argument that coping variables mediate the relationship between perceived control and emotional adjustment.

Examination of the squared multiple correlations for the dependent variables (Table 19) also suggests that Model $C$ in which perceived control mediates the relationship between the coping variables and emotional adjustment fits the data better

Table 19

Squared Multiple Correlations for Dependent Variables (Variance Explained)

\begin{tabular}{lc}
\hline Model/Dependent Variables & $\underline{\mathrm{R}}^{2}$ \\
\hline Model C & .526 \\
Perceived control & .552 \\
Emotional adjustment & \\
& \\
Model F & .001 \\
Seek and use social support & .002 \\
Distancing & .200 \\
Cognitive escape-avoidance & .148 \\
Behavioral escape-avoidance & .052 \\
Focus on the positive & .547 \\
Emotional adjustment & \\
\hline
\end{tabular}


than Model $\mathrm{F}$ with the coping variable as mediator. Both models $\mathrm{C}$ and $\mathrm{F}$ explain about $55 \%$ of the variance in emotional adjustment. However, while the coping variables collectively explain about $50 \%$ of the variance in perceived control, substantially less of the variance in any of the coping variables is explained by perceived control. About $20 \%$ of the variance in cognitive escape-avoidance and $15 \%$ of the variance in behavioral escape-avoidance is explained by perceived control.

Hypothesis 4: Perceived control will explain variation in adjustment over and above that explained by coping alone.

H4 was examined using hierarchical regression. Variables were entered in two steps. The proportion of variance explained, adjisted $\underline{R}^{2}$, and incremental variance explained are displayed in Table 20. The five coping variables were entered on the first step and explained $42.5 \%$ of the variance in emotional adjustment. At step 2, the control variables were entered. Together the coping and control variables explained over half, $52.7 \%$, of the variance in emotional adjustment. The control variables as a set explained $10.2 \%$ of the variance in emotional adjustment over and above that which was explained by the coping variables. 
Table 20

Hierarchical Regression Results Predicting Adjustment from Four Areas of $\underline{\text { Control }}$

\begin{tabular}{lccccc}
\hline Step/Variable & $\underline{\mathrm{R}}^{2}$ & Adjusted $^{\mathrm{R}^{2}}$ & $\underline{\mathrm{F}}$ & $\underline{\mathrm{R}}^{2}$ Increment & $\underline{\text { E Increment }}$ \\
\hline & & & & & \\
1. Coping & .425 & .402 & $19.04^{*}$ & & \\
2. Control & .527 & .493 & $15.48^{*}$ & .102 & $6.74^{*}$ \\
& & & & & \\
\hline$\underline{\mathrm{N}}=137$ & & & & & \\
& & & & &
\end{tabular}

Note: Control of consequences $=$ symptom-emotion control, relationship control, and medical care control. ${ }^{*} \mathrm{p}<.05$

\section{Discussion}

This research was based on an extension of Folkman's theory of personal control, stress, and coping. In Folkman's (1984) theory, personal control was seen as both an antecedent and an outcome of coping. In the revised model used in this research, control expectations were viewed as an antecedent of coping and perceived, or experienced, control was seen as a mediator of coping and emotional adjustment. Only the coping $\rightarrow$ perceived control $\rightarrow$ emotional adjustment portion of the model was examined in the current study. Even within this segment of the model, assumptions 
Coping and Control 66

have been made about the directionality, or causal ordering, of the model. Since crosssectional data were examined, findings about the directionality of the model are not conclusive. However, the findings were generally consistent with the revised model. The relationships among coping, perceived control, and emotional adjustment are discussed in greater detail below following discussions of findings more specific to coping and to perceived control.

\section{Patterns of Coping}

As noted earlier, all five patterns of coping identified by Dunkel-Schetter et al. (1992) included items which might be considered emotion focused. The social support pattern, however, was not unidimensional. The three items which loaded lowest on the social support factor were clearly problem focused. These items were tried not to close of options (.42), made a plan of action and followed it (.40), concentrated on the next step (.39). It was hypothesized that the blending of social support and problem-focused items occurred because the WOC-CA inventory contained relatively few items that directly addressed problem solving. Thus, it was expected that with the addition of five new problem-focused items written specifically for use in this study, a problem-focused pattern of coping would emerge. Despite the addition of the five new problem-focused items, the expected problem-focused pattern of coping failed to be sufficiently distinct from seek and use social to support to warrant its inclusion in subsequent analyses as a separate construct.

Since problem-focused coping has a prominent role in theories of coping presented by Folkman (1984) and by Rothbaum, Weisz, and Snyder (1982), it seemed 
particularly perplexing that a problem-focused pattern of coping did not emerge with the addition of the new problem-focused items. One possible explanation for the lack of a clearly problem-focused pattern of coping may be that the social support pattern has been mislabeled. It was argued earlier that the cancer patient is confronted with a myriad of stressors. Among these are not only uncertainty about the course of the disease and its treatment, but changes in social relationships as well. Perhaps the pattern labeled by Dunkel-Schetter and associates (1992) as Seek and Use Social Support might also have been labeled Problem Focused. The items talked to someone about how I was feeling and asked a friend or relative for advice could be considered problem-focused attempts to deal with relationship problems. Two other items, talked to someone to find out more and talked to someone who could do something seemed to blend social support and problem focused aspects. Given the complexity of the stressors and of the coping items, it may be that seeking social support should be considered a problem-focused rather than emotion-focused coping strategy.

\section{Perceived Control and Emotional Adjustment}

The current study provided the opportunity to explore whether it is more important for patients to believe that they can control the emotions and symptoms related to their cancers than it is for them to believe that they can control the course of their diseases. Thompson et al. (1993) examined partial correlations, controlling for marital satisfaction and physical functioning, of each of the four areas of control (emotion-symptom, relationship, medical care, and disease) with patient maladjustment. All four areas of control were significantly related to maladjustment, but symptom- 
Coping and Control 68

emotion control explained substantially more variance than did disease control. Jenkins and Pargament (1988) also examined correlations and concluded, as did Thompson, that it may be more important to believe that one can control the consequences of the cancer than to control the cancer itself.

Some support for the notion that controlling one's symptoms and emotions is more important to overall adjustment (or maladjustment) than controlling the progression of the disease was found in this study. After controlling for health status, symptom-emotion control was more strongly associated with emotional adjustment than was disease control. However, it should be noted that all four areas of control (symptom-emotion, relationship, medical care, and disease control) had relatively high zero-order correlations with emotional adjustment. Although the areas of control are highly related, they are not interchangeable. With the exception of medical care control, each of the other areas of control explains variance in emotional adjustment that cannot be explained by the other variables. These results should not be interpreted as suggesting that medical care control is not an important contributor to emotional adjustment. On the contrary, medical care control was strongly correlated with emotional adjustment and to the other areas of control, especially symptom-emotion control. From this analysis, it is not possible to predict the effect on adjustment if medical care control were absent, but given the strong correlations with symptomemotion control and emotional adjustment, negative consequences would seem likely in the absence of medical care control. 
Coping, Perceived Control, and Emotional Adjustment - The Revised Model

All five coping patterns influenced perceptions of control. Seeking and using social support, distancing, and focusing on the positive had a positive influence on perceived control, while the escape-avoidant patterns had a negative influence on perceived control. Among the cancer patients in this study, high use of behavioral and cognitive escape-avoidance and low use of focusing on the positive tended to be associated with low perceived control. As in earlier studies, escape-avoidant coping tended to be associated with poorer emotional adjustment, while more active coping such as focusing on the positive was associated with better adjustment (Dunkel-Schetter et al., 1992; Friedman et al., 1989; Stanton \& Snider, 1993). As expected, high levels of perceived control had a positive influence on emotional adjustment.

The joint influence of coping and perceived control on emotional adjustment was also examined. The original analysis plan was to use the five coping patterns as indicators of a latent variable representing coping and the four areas of control as indicators of perceived control in a CSM to predict emotional adjustment. Although the patterns of coping were significantly correlated with one another, their common variance was not predictive of perceived control or emotional adjustment. Apparently, the unique rather than the shared variance of the individual coping patterns is associated with differential levels of perceived control and emotional adjustment. Thus, rather than using the five patterns of coping as indicators of a single coping variable, each pattern was used as a separate variable in the analysis. The findings were only partially consistent with the proposed model in which perceived control was expected to mediate 
the relationship between patterns of coping and emotional adjustment. All five coping patterns influenced perceived control, and perceived control was strongly associated with emotional adjustment. Cognitive escape-avoidance exerted an indirect influence on emotional adjustment through perceived control. Behavioral escape-avoidance and focus on the positive not only exerted indirect influences but also had direct effects on emotional adjustment. While social support and distancing were not predictive of emotional adjustment, they did predict perceived control.

An alternative model which conceptualized the coping variables as mediators of perceived control and emotional adjustment was also examined. The coping patterns did not clearly mediate the relationship between perceived control and emotional adjustment. The role of perceived control was reduced when the coping patterns were introduced as mediator variables; however, the role of perceived control was also reduced when the coping variables were merely present in the model as predictors of emotional adjustment. While it seems reasonable that some measure of control would have an influence on the coping patterns used by cancer patients, the measure would need to be one that focused on expectations for control rather than on experienced control. The measures of control used in the current study were of experienced control. Patients were asked about the amount and effectiveness of their control in the four areas. Future research is necessary to examine the multiple roles of control in a model of stress, coping, control, and adjustment such as that presented early in this paper.

It was proposed that a major function of coping may be to regain perceptions of control that are threatened by the cancer experience, and that perceived control 
Coping and Control 71

mediates the relationship between coping and emotional adjustment. The findings of this study provide partial support for this view. Perceived control fully mediated the effect of only one of the coping patterns (cognitive escape-avoidance) on emotional adjustment. Behavioral escape-avoidance and focus on the positive had both direct and indirect (mediated) influences on emotional adjustment. Thus, any efforts on the part of health care workers to bolster cancer patients' emotional adjustment should focus on both teaching positive coping strategies and on efforts to increase perceptions of control. Interestingly, while support groups and counseling efforts are available to cancer patients through many hospitals, social support was not shown to be significantly associated with emotional adjustment, but was significantly associated with perceived control. Perhaps support groups and counselors should make particular efforts to help patients learn methods of focusing on the positive (e.g., focusing on what is important in life or on changing something about the self in a positive way, etc.) and on substituting other coping strategies for escape-avoidant patterns. In addition to providing support groups and counseling, special efforts need to be made to identify patients with low perceptions of control who may be engaging in escape-avoidant coping patterns. These patients are particularly at risk for poor emotional outcomes and might be helped to find aspects of their cancer situation over which they can exert some measure of control.

The challenge for cancer patients would seem to be in avoiding escape-avoidant coping patterns and maintaining a strong sense of control. This study has lent further support to the notion that when outcomes are poor, as indicated by poor/fair health 
status in the current study, the patient may be able to maintain positive emotional adjustment by achieving high levels of perceived control over the consequences of the cancer even when disease control is not possible.

\section{Limitations}

One limitation of the current study is that the sample is likely skewed toward cancer patients who are achieving good outcomes. Response rates were somewhat lower than expected (30\%) and may reflect the length of the questionnaire. It seems likely that patients who may be experiencing poor outcomes may not have had the stamina to complete the questionnaire.

Another limitation was the inability to link specific stressors to their associated coping patterns. The cancer patient is confronted with a myriad of stressors. Since the stressors change over the course of the disease and its treatment, the coping strategies reported by an individual likely reflect responses to many stressors. Further research is needed to address questions related to the control appraisal portion of the proposed model and to determine whether individual coping patterns are associated with individual stressors.

Other limitations include the self-report and cross-sectional design of the study. It is possible that self-reports of coping do not accurately reflect actual behaviors. Further research, perhaps including observation and/or informant reports, would be useful. Finally, the cross-sectional design makes it impossible to establish causation. Although the directional arrows included in the model seem to suggest causation, at most we can conclude that the data does not rule out the proposed model. Additional 
research employing longitudinal or experimental designs is necessary to establish causation. A longitudinal study such as that reported by Stanton and Snider (1993) that collected data prebiopsy, postbiopsy, and postsurgery would help to further sort out the relationships among coping, control, and adjustment to cancer. Measures of control expectations as well as experienced control should be collected.

Despite these limitations, this study has made an important contribution toward understanding how coping and perceived control may jointly influence emotional adjustment among cancer patients. The findings suggest that coping efforts have direct influences, as well as indirect influences through perceived control, on emotional adjustment. The implications for cancer patients and health care workers have also been discussed. To the extent that cancer patients are able to focus on positive aspects of their lives and find areas within their cancer experience over which they can exert some control, they may be able to maintain positive emotional adjustment. Helping patients to avoid cognitive and behavioral escape-avoidant coping patterns that appear to undermine perceived control may be a particularly important goal for health care workers. 


\section{References}

Baron, R. M., \& Kenny, D. A. (1986). The moderator-mediator variable distinction in social psychological research: Conceptual, strategic and statistical considerations. Journal of Personality and Social Psychology, 51 (6), 1173-1 182.

Burish, T. G., Carey, M. P., Wallston, K. A., Stein, M. J., Jamison, R. N., \& Lyles, J. N. (1984). Health locus of control and chronic disease: An external orientation may be advantageous. Journal of Social and Clinical Psychology, 2(4), 326-332.

Dunkel-Schetter, C., Feinstein, L. G., Taylor, S. E., \& Falke, R. L. (1992). Patterns of coping with cancer. Health Psychology 11(2), 79-87.

Felton, B. J., \& Revenson, T. A. (1984). Coping with chronic illness: A study of illness controllability and the influence of coping strategies on psychological adjustment. Journal of Consulting and Clinical Psychology 52(3), 343-353.

Folkman, S. (1984). Personal control and stress and coping processes: A theoretical analysis. Journal of Personality and Social Psychology, 46 (4), 839-852.

Folkman, S., \& Lazarus, R. S. (1980). An analysis of coping in a middle-aged community sample. Journal of Health and Social Behavior, 21, 219-239.

Friedman, L. C., Baer, P. E., Lewy, A., Lane, M., \& Smith, F. E. (1989). Predictors of psychosocial adjustment to breast cancer. Journal of Psychosocial Oncology, 6(1/2), 75-94.

Jenkins, R. A., \& Pargament, K. I. (1988). Cognitive appraisals in cancer patients. Social Science and Medicine, 26 (6), 625-633.

Lazarus, R. S., \& Folkman, S. (1984). Stress, Appraisal, and Coping. New 
York: Springer.

Lorr, M., \& McNair, D. (1988). Profile of Mood States: Bi-polar form (POMSBI). San Diego: Educational and Industrial Testing Service.

Lowery, B. J., Jacobsen, B. S., \& DuCette, J. (1993). Causal attribution, control, and adjustment to breast cancer. Journal of Psychosocial Oncology 10(4), 3753.

Rothbaum, F., Weisz, J. R., \& Snyder, S. S. (1982). Changing the world and changing the self: A two-process model of perceived control. Journal of Personality and Social Psychology, 42(1), 5-37.

Skinner, E. A. (1995). Is more control better? A simple answer to a complex question. Manuscript submitted for publication.

Stanton, A. L., \& Snider, P. R. (1993). Coping with a breast cancer diagnosis: A prospective study. Health Psychology 12 (1), 16-23.

Taylor, S. E. (1983). Adjustment to threatening events: A theory of cognitive adaptation. American Psychologist, 38 (11), 1161-1173.

Taylor, S. E., \& Brown, J. D. (1988). Illusion and well-being: A social psychological perspective on mental health. Psychological Bulletin, 103, 193-210.

Taylor, S. E., Helgeson, V. S., Reed, G. M., \& Skokan, L. A. (1991). Selfgenerated feelings of control and adjustment to physical illness. Journal of Social Issues, 47(4), 91-109.

Taylor, S. E., Lichtman, R. R., \& Wood, J. V. (1984). Attributions, beliefs about control and adjustment to breast cancer. Journal of Personality and Social Psychology, 
Coping and Control 76

46(3), 489-502.

Thompson, S. C., Sobolew-Shubin, A., Galbraith, M. E. Schwankovsky, L., \& Cruzen, D. (1993). Maintaining perceptions of control: Finding perceived control in low-control circumstances. Journal of Personality and Social Psychology. 64 (2), 293304.

Wortman, C. B., \& Dunkel-Schetter, C. (1979). Interpersonal relationships and cancer: A theoretical analysis. Journal of Social Issues, 35, 120-155 
Appendix A

Ways of Coping - Cancer Subscales

\section{Five Patterns of Coping}

\section{Seek and use social support}

Talked to someone to find out more

Talked to someone about how feeling

Talked to someone who could do something

Let my feelings out somehow

Tried to get professional help

Tried to find out as much as I could

Looked for sympathy or understanding

Asked a friend or relative for advice

Tried not to close off options

Made a plan of action and followed it

Concentrated on the next step

\section{Cognitive Escape-Avoidance ${ }^{b}$}

Hoped a miracle would happen

Prayed

Prepared for the worst

Wished the situation would go away or be over

Had fantasies/wishes about how it might turn out

Went over in my mind what I would say or do

Went along with fate

Depended mostly on others to handle things

Slept more than usual

\section{Six Patterns of Coping}

\section{Seek and use social support}

Talked to someone to find out more

Talked to someone about how feeling

Talked to someone who could do something

Let my feelings out somehow

Looked for sympathy or understanding

Asked a friend or relative for advice

\section{Cognitive Escape-Avoidance}

(Same as for 5 patterns)

\section{Distancing}

(Same as for 5 patterns)

\section{Focus on the Positive}

(Same as for 5 patterns) 
Five Patterns of Coping (continued)

\section{Distancinge}

Tried to keep my feelings from interfering

Didn't let it get to me; refused to think about it

Made light of it; refused to get too serious

Went on as if it were not happening

Tried to keep my feelings to myself

Looked for silver lining, looked for the bright side

Treated the illness as a challenge

Knew what had to be done, so increased efforts

Tried to forget the whole thing

Kept others from knowing how bad things were

Reminded myself how much worse things could be

Lived one day at a time/took one step at a time

Focus on the positive ${ }^{d}$

Found new faith

Rediscovered what is important in life

Changed or grew as a person in a good way

Changed something about myself

Came out of the experience better than before

Changed something so things will turn out

Was inspired to be creative

Thought of how a person I admire would act

\section{Behavioral Escape-Avoidance ${ }^{e}$}

Avoided being with people

Tried to make myself feel better by eating, drinking,

smoking, or drug use

Took a big chance and did something risky

\section{Six Patterns of Coping (continued)}

\section{Behavioral Escape-Avoidance}

(Same as for 5 patterns)

\section{Problem-Focused}

Tried to get professional help

Tried to find out as much as I could

Tried not to close off options

Made a plan of action and followed it

Concentrated on the next step

Followed my doctor's orders carefully

Changed my diet

Tried to get more exercise

Read books and magazine articles to

find out more

Learned ways to control pain 


\section{Five Patterns of Coping (continued)}

\section{Behavioral Escape-Avoidance}

Took it out on other people

Came up with different solutions

Waited to see what would happen before acting

Criticized or lectured myself

Did something just to do something

Tried not to act too hastily

${ }^{\mathrm{A} A l p h a}=.87 .{ }^{\mathrm{b}} \mathrm{Alpha}=.73 .{ }^{\mathrm{C}} \mathrm{Alpha}=.77 .{ }^{\mathrm{d}} \mathrm{Alpha}=.84 . \quad{ }^{\circ} \mathrm{Alpha}=.72$.

Italics indicate potential additional items. 
Appendix B

Control Items

\section{Symptom-emotion Control: *}

(1) To what extent do you feel that you have control over the emotions associated with your cancer?

(2) How effective have your efforts to control your emotions been?

(3) To what extent do you feel that you have control over the physical symptoms associated with your cancer?

(4) How effective have your efforts to control your physical symptoms been?

\section{Relationship Control:}

(1) To what extent do you feel that you have control over your relationship with your spouse?

(2) How effective have your efforts to control your relationship with your spouse been?

(3) To what extent do you feel that you have control over your relationships with your family?

(4) How effective have your efforts to control your relationships with your family been?

(5) To what extent do you feel that you have control over your relationships with your friends?

(6) How effective have your efforts to control your relationships with your friends been?

\section{Medical Care Control:}

(1) To what extent do you feel that you have control over the medical treatment that you receive for your cancer?

(2) How effective have your efforts to control your medical treatment been?

(3) To what extent do you feel that you have control over the medical information that you have received?

(4) How effective have your efforts to control the medical information that you have received been?

\section{Disease Control: ${ }^{d}$}

(1) To what extent do you feel that you have control over the progression of your cancer?

(2) How effective have your efforts to control the progression of the cancer been?

${ }^{\mathrm{a} A l p h a}=.84 .{ }^{\mathrm{b}} \mathrm{Alpha}=.92 .{ }^{\mathrm{c} A l p h a}=.85 .{ }^{\mathrm{d}} \mathrm{Alpha}=.75$. 